\title{
Targeting Oncogenic Src Homology 2 Domain-Containing Phosphatase 2 (SHP2) by Inhibiting Its Protein-Protein Interactions
}

\author{
Sara Bobone, Luca Pannone, Barbara Biondi, Maja Solman, Elisabetta Flex, Viviana Claudia Canale, \\ Paolo Calligari, Chiara De Faveri, Tommaso Gandini, Andrea Quercioli, Giuseppe Torini, \\ Martina Venditti, Antonella Lauri, Giulia Fasano, Jelmer Hoeksma, Valerio Santucci, Giada Cattani, \\ Alessio Bocedi, Giovanna Carpentieri, Valentina Tirelli, Massimo Sanchez, Cristina Peggion, \\ Fernando Formaggio, Jeroen den Hertog, Simone Martinelli, ${ }^{\bullet}$ Gianfranco Bocchinfuso, \\ Marco Tartaglia, and Lorenzo Stella*
}

Cite This: J. Med. Chem. 2021, 64, 15973-15990

Read Online

ABSTRACT: We developed a new class of inhibitors of protein-protein interactions of the SHP2 phosphatase, which is pivotal in cell signaling and represents a central target in the therapy of cancer and rare diseases. Currently available SHP2 inhibitors target the catalytic site or an allosteric pocket but lack specificity or are ineffective for disease-associated SHP2 mutants. Considering that pathogenic lesions cause signaling hyperactivation due to increased levels of SHP2 association with cognate proteins, we developed peptide-based molecules with nanomolar affinity for the N-terminal Src homology domain of SHP2, good selectivity, stability to degradation, and an affinity for pathogenic variants of SHP2 that is $2-20$ times higher than for the wild-type protein. The best peptide reverted the effects of a pathogenic variant (D61G) in zebrafish embryos. Our results provide a novel route for SHP2-targeted therapies and a tool for investigating the role of protein-protein interactions in the function of SHP2.

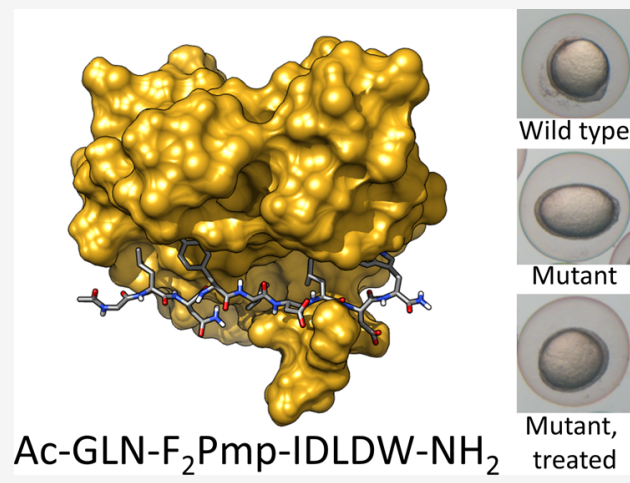

\section{INTRODUCTION}

The Src homology 2 (SH2) domain-containing phosphatase 2 (SHP2), encoded by the PTPN11 gene, ${ }^{1}$ is ubiquitously expressed and mediates signal transduction downstream of various receptor tyrosine kinases (RTKs). This phosphatase is required for full and sustained activation of the RAS/MAP kinase pathway ${ }^{2}$ and modulates signaling also through the PI3K-AKT and JAK-STAT pathways, among others. SHP2 is involved in the regulation of multiple cell processes, including proliferation, survival, differentiation, and migration, and its functional upregulation contributes to oncogenesis and underlies developmental disorders. ${ }^{1}$ Somatically acquired, gain of function mutations in PTPN11 are the major cause of juvenile myelomonocytic leukemia (JMML), ${ }^{3}$ a rare and aggressive myelodysplastic/myeloproliferative disorder of early childhood with a very poor prognosis, for which no drugs are presently available. Somatic PTPN11 mutations also occur in childhood myelodysplastic syndromes, acute monocytic leukemia (AMoL, FAB M5), and acute lymphoblastic leukemia (ALL, "common" subtype). . $^{3,4}$ More rarely, activating mutations in this gene are found in adult myelodysplastic syndromes, chronic myelomonocytic leukemia, and solid tumors, including neuroblastoma, glioma, embryonal rhabdomyosarcoma, lung cancer, colon cancer, and melanoma. In addition to malignancies driven by PTPN11 mutations, several forms of cancer are linked to the activity of wild-type SHP2. SHP2 is required for survival of RTK-driven cancer cells, ${ }^{5}$ is a central node in intrinsic and acquired resistance to targeted cancer drugs, ${ }^{6}$ and plays a role as a mediator of immune checkpoint pathways ${ }^{7,8}$ and of induction of gastric carcinoma by Helicobacter pylori. ${ }^{9,10}$

In addition to its role in cancer, SHP2 is involved in two disorders that belong to a family of rare diseases collectively known as RASopathies. Germline missense mutations in PTPN11 occur in $\sim 50 \%$ of individuals affected by Noonan syndrome (NS), ${ }^{11}$ one of the most common nonchromosomal disorders affecting development and growth, ${ }^{12}$ and in $~ 90 \%$ of patients affected by the clinically related Noonan syndrome with multiple lentigines (NSML, formerly known as LEOPARD syndrome). ${ }^{13,14}$ RASopathies are characterized by congenital cardiac anomalies, hypertrophic cardiomyopathy,

Received: August 2, 2021

Published: October 29, 2021 


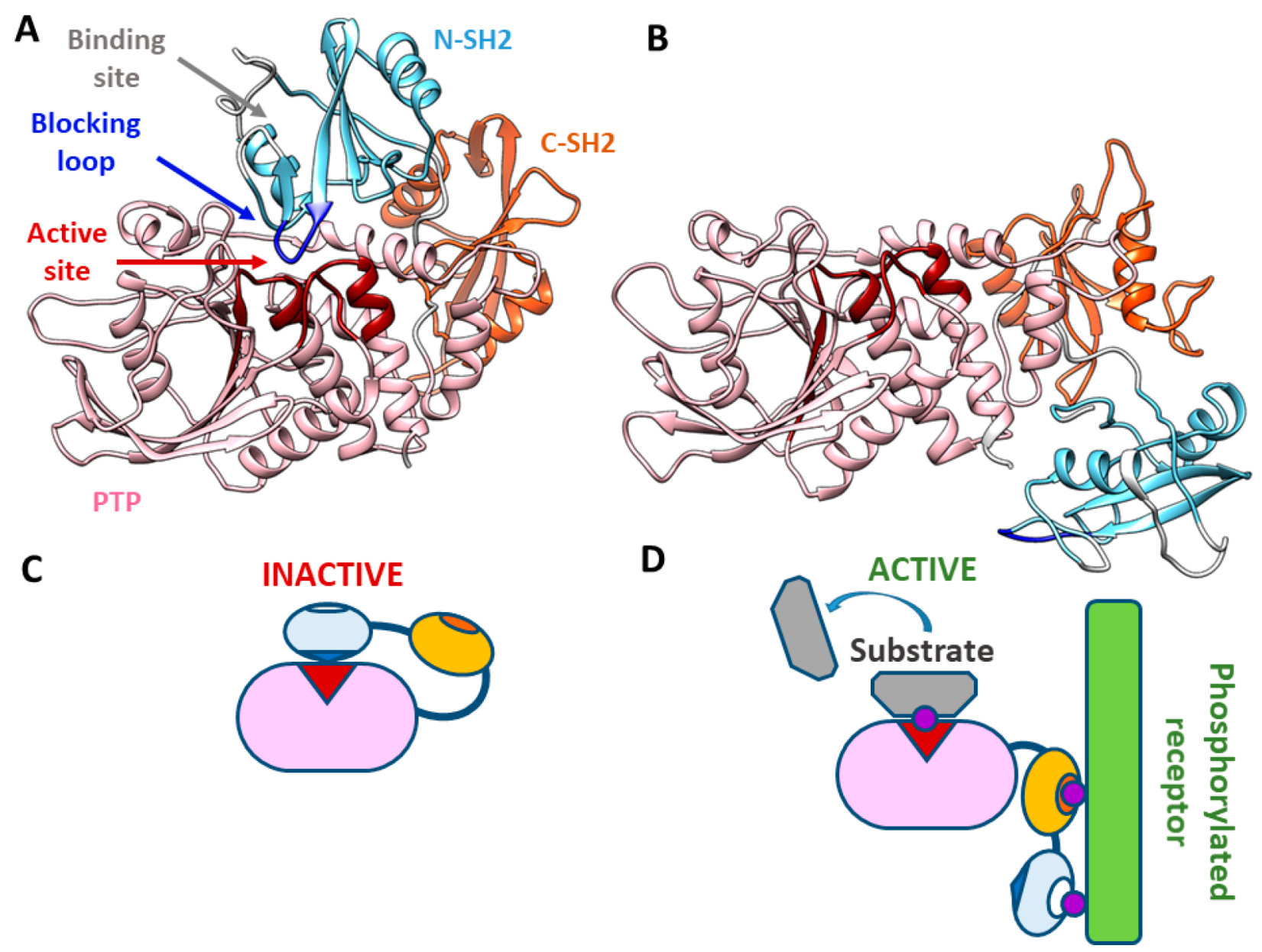

Figure 1. SHP2 structure and scheme of the activation process. (A) Crystallographic structure of the closed, autoinhibited state of SHP2 (PDB entry 2SHP). The active site (red) of the PTP domain (pink) is blocked by the N-SH2 domain (light blue) and particularly by its blocking loop (DE loop, blue). Access to the binding site of the N-SH2 domain is blocked by two loops (EF and BG, white). The C-SH2 domain is colored orange. (B) Crystallographic structure of the open, active state of SHP2 (PDB entry 6CRF). With respect to the autoinhibited state, the N-SH2 domain moves to the other side of the PTP domain, freeing the active site. At the same time, the EF and BG loops open and the N-SH2 binding site is accessible. Segments missing in the experimental structures were modeled as previously described. ${ }^{21}$ (C) Schematic model of the autoinhibited state. Under basal conditions, the protein is autoinhibited by the N-SH2 domain, blocking the active site. (D) Schematic model of the active state. Upon interaction with binding partners, an open, active conformation is stabilized.

short stature, musculoskeletal anomalies, facial dysmorphisms, variable intellectual disability, and susceptibility to certain malignancies. ${ }^{15}$ To date, the only treatment in use for NS and related disorders is growth hormone therapy to improve linear growth. $^{12}$

The structure of SHP2 includes two Src homology 2 (SH2) domains, called $\mathrm{N}-\mathrm{SH} 2$ and $\mathrm{C}-\mathrm{SH} 2$, followed by the catalytic PTP domain, and an unstructured C-terminal tail (Figure 1). ${ }^{1,16} \mathrm{SH} 2$ domains are recognition elements that bind protein sequences containing a phosphorylated tyrosine $(\mathrm{pY}){ }^{17,18}$ In SHP2, they mediate association with RTKs, cytokine receptors, cell adhesion molecules, and scaffolding adaptors. Therefore, SHP2 (together with the closely related SHP1) is recruited (through its $\mathrm{SH} 2$ domains) by motifs containing two pYs and dephosphorylates other (or even the same) pYs through its PTP domain.

Under basal conditions, the N-SH2 domain blocks the active site of the PTP domain, inserting a loop (DE or "blocking" loop) into the catalytic pocket; ${ }^{16}$ consistently, the basal activity of SHP2 is very low. Association of SHP2 with its binding partners through the $\mathrm{SH} 2$ domains favors the release of this autoinhibitory interaction, making the catalytic site available to substrates and causing activation (Figure 1). ${ }^{19-23}$ Specifically, structures of the N-SH2 domain associated with phosphopeptide sequences show that association with binding partners induces a conformational change in the blocking loop, which loses complementarity to the active site. ${ }^{24}$ At the same time, the N-SH2/PTP interaction allosterically controls the conformation of the N-SH2 domain binding site. Structures of the autoinhibited protein show that the binding site of the $\mathrm{N}-\mathrm{SH} 2$ domain is closed by two loops (EF and BG). By contrast, in structures of the isolated N-SH2 domain, ${ }^{24}$ or the recently reported structure of the active state of $\mathrm{SHP} 2,{ }^{23}$ the binding site is open (Figure 1). Consequently, we and others have hypothesized that the transition between the closed, autoinhibited state and the open, active conformation is coupled to an increased affinity for binding partners. ${ }^{19,21-23}$

The spectrum of pathogenic PTPN11 mutations is generally consistent with this picture of SHP2 regulation. Most mutations cluster at the N-SH2/PTP interface, destabilizing the interaction between these two domains and causing constitutive activation of the phosphatase. ${ }^{19-21}$ These mutations concomitantly induce an increased responsiveness to activation by association of bisphosphorylated sequences 
with the SH2 domains. ${ }^{19,21-23}$ Other mutations localize in the binding site of the $\mathrm{SH} 2$ domains and simply cause an increased affinity for phosphorylated binding partners. ${ }^{20}$ In all cases, the final effect is an upregulation of the RAS/MAPK signal transduction pathway.

All of the findings reported above clearly indicate SHP2 as an important molecular target for cancer and RASopathies. ${ }^{25,26}$ Research efforts in SHP2-targeted drug discovery have long been focused mainly on active-site inhibitors, ${ }^{27,28}$ which however are affected by a lack of target specificity. ${ }^{26,2729}$

Allosteric inhibitors stabilizing the autoinhibited structure of SHP2 by binding to a pocket located at the interdomain interface in the closed conformation of the phosphatase represent a recent, alternative pharmacological strategy. $5,25,26,30-35$ SHP099, an inhibitor developed by Novartis, is finding promising applications in the treatment of RTKdriven cancers ${ }^{33}$ and in combined therapy against drug resistant cells. ${ }^{6}$ However, allosteric inhibitors are generally poorly effective in the case of activating PTPN11 mutants, because their binding site is lost in the open conformation of the enzyme. ${ }^{23,25}$

Due to the allosteric mechanism described above, SHP2 activation and its association with binding partners are coupled events. Therefore, the effect of NS- and leukemia-causing mutations destabilizing the autoinhibited conformation is twofold: they cause an increase in the phosphatase activity of the protein but at the same time favor the $\mathrm{N}-\mathrm{SH} 2$ conformation suitable for binding phosphorylated proteins, thus increasing the overall responsiveness of SHP2 to its interaction partners. Several lines of evidence indicate that the second event, rather than the enhanced basal activity, is essential for the abnormal activation of the RAS/MAPK pathway. Some pathogenic variants, such as the NS-associated p.T42A, simply increase the binding affinity of the N-SH2 domain, without causing basal activation; ${ }^{19,22}$ in addition, the ability of SHP2 to associate with binding partners is preserved in all of the disease-associated PTPN11 mutations. ${ }^{20,36,37}$ Truncated constructs with deletion or partial deletion of the $\mathrm{N}-\mathrm{SH} 2$ domain cause a dramatic increase in the enzymatic activity of SHP2 and, at the same time, a complete loss of its ability to bind signaling partners. These constructs do not affect development in heterozygous mice ${ }^{2}$ and do not cause any aberrant phenotype in cells. ${ }^{2,9,38}$ However, cellular morphological changes (hummingbird phenotype) were observed when the truncated construct was targeted to cellular membranes by adding a membrane-localization signal, ${ }^{9}$ demonstrating the importance of proper cellular localization, normally mediated by the $\mathrm{SH} 2$ domains. The relevance of association of SHP2 with its binding partners for its role in aberrant signaling has been demonstrated also by a study of monobodies targeting the $\mathrm{N}-\mathrm{SH} 2$ domain and disrupting its association with adaptor proteins. Expression of these monobodies in cancer cells carrying the activating p.V45L substitution abolished ERK1/2 phosphorylation almost completely. ${ }^{39}$ Similarly, Kertész and co-workers ${ }^{40}$ reported that the natural SHP2 binding motif of Gab1, when delivered into immune cells, modulated phosphorylation patterns.

An example of the opposite situation, in which binding is preserved and the catalytic activity is impaired, is provided by PTPN11 mutations causing NSML, such as p.T468M. This class of amino acid substitutions is located in the proximity of the PTP active site, at the PTP/N-SH2 interface, and have a twofold effect: they destabilize the closed state of the protein and consequently promote association of SHP2 with signaling partners; at the same time, they perturb the active site and therefore strongly impair the catalytic activity of the phosphatase. Interestingly, the phenotype of NSML is very similar to that of NS, and these mutations still allow the activation of multiple effector pathways. ${ }^{2,41}$

Overall, these findings strongly suggest that a mere enhancement of SHP2 catalytic activity is not sufficient to cause disease and indicate that an increased level of association with binding partners plays a major role in the pathogenic mechanism associated with PTPN11 pathogenic variants. Therefore, inhibition of binding of SHP2 to other proteins through its $\mathrm{SH} 2$ domains represents a promising alternative pharmaceutical strategy. No molecules targeting the $\mathrm{SH} 2$ domains of SHP2 for therapeutic purposes have been developed so far, even though $\mathrm{SH} 2$ domains in general have received a great deal of attention as potential pharmaceutical targets. ${ }^{42,43}$ These recognition units generally have only moderate affinity and selectivity for cognate phosphorylated sequences, with dissociation constants in the range of $0.1-10$ $\mu \mathrm{M} .{ }^{42,44-46}$ However, we recently characterized the structural determinants of phosphopeptide binding by the $\mathrm{N}-\mathrm{SH} 2$ domain of SHP2, ${ }^{18}$ and our data indicate this particular domain as a favorable exception, because its peculiar features make significantly higher affinities possible.

On the basis of these considerations, we explored the possibility of targeting SHP2 protein-protein interactions (PPIs), rather than its catalytic activity. We developed a peptide-based molecule with nanomolar affinity for the N-SH2 domain of SHP2, high specificity, and resistance to degradation. This inhibitor rescued the mortality and developmental defects induced by a pathogenic mutation in vivo. Our results provide a novel route for SHP2-targeted therapies and offer a new tool for further investigating the role of SHP2 PPIs in the signaling cascades controlled by this phosphatase.

\section{RESULTS}

Characterization of IRS-1 pY1172/N-SH2 Binding. The IRS-1 pY1172 Peptide Binds the N-SH2 Domain with Nanomolar Affinity. The peptide corresponding to pY1172 (rat sequence, SLN-pY-IDLDLVKD) or pY1179 (human sequence, GLN-pY-IDLDLVKD) of insulin receptor substrate 1 (IRS-1) has one of the highest known binding affinities for the N-SH2 domain of SHP2. ${ }^{18,47}$ On the basis of our study of the structural determinants of a high affinity for this domain, the IRS-1 pY1172 sequence is near to optimal in several respects, because it has apolar residues at positions $+1,+3$, and +5 , which point toward the hydrophobic groove in the $\mathrm{N}-\mathrm{SH} 2$ structure, and anionic amino acids at positions +2 and +4 , which can interact with a peculiar KxK motif in the BG loop. ${ }^{18}$

The binding affinity of the IRS-1 pY1172 peptide has been characterized in several literature studies. Unfortunately, these results are extremely contradictory, as reported in Table S1, with dissociation constants ranging from $\sim 10 \mathrm{nM}$ to $\sim 10 \mu \mathrm{M}$. Several possible factors can be invoked to explain these discrepancies, including the effect of radioactive labels, ${ }^{48}$ dimerization of GST-N-SH2 constructs ${ }^{49,50}$ even at low nanomolar concentrations, ${ }^{51}$ or the sensitivity of the technique. $^{19}$

Considering these difficulties, in this study, we developed a fluorescence anisotropy binding assay. In a direct binding experiment, the fluorescently labeled peptide IRS-1 pY1172 
Table 1. Peptide Sequences Investigated in This Study ${ }^{a}$

\begin{tabular}{|c|c|c|c|c|c|c|c|}
\hline \multirow[b]{2}{*}{ N. } & \multirow[b]{2}{*}{ Abbreviation } & \multirow{2}{*}{\multicolumn{2}{|c|}{ Sequence }} & \multirow{2}{*}{$\begin{array}{c}\text { HPLC }^{*} \\
\mathbf{R}_{\mathbf{t}}(\mathrm{min})\end{array}$} & \multirow[b]{2}{*}{ Purity } & \multicolumn{2}{|c|}{ Mass } \\
\hline & & & & & & Calc & Exp \\
\hline 1 & P9 & GLN-p & -IDLDL & $21.2^{a}$ & $95 \%$ & 1156.5 & 1156.6 \\
\hline 1a & P8 & $\mathrm{LN}-\mathrm{p}$ & -IDLDL & $24.3^{a}$ & $92 \%$ & 1099.5 & 1099.4 \\
\hline $1 \mathrm{~b}$ & P7 & $N-p$ & -IDLDL & $16.9^{a}$ & $92 \%$ & 986.4 & 986.3 \\
\hline 2 & P8W5 & LN-p & -IDLDW & $12.5^{\circ}$ & $95 \%$ & 1172.4951 & 1172.4366 \\
\hline 3 & P8F5 & $\mathrm{LN}-\mathrm{p}$ & -IDLDF & $15.1^{e}$ & $95 \%$ & 1133.2 & 1133.5 \\
\hline 4 & P8E4W5 & $L N-p$ & -IDLEW & $12.4^{c}$ & $98 \%$ & 1186.2 & 1186.5 \\
\hline 5 & OP & GLN- F & $\mathrm{np}-\mathrm{IDLDW}$ & $14.3^{e}$ & $97 \%$ & 1263.5184 & 1263.5028 \\
\hline $1 \mathrm{~L}$ & CF-P9 & CF-GLN-p) & -IDLDL & $14.9^{b}$ & $93 \%$ & 1473.5 & 1473.6 \\
\hline $1 \mathrm{La}$ & CF-P9Y0 & CF-GLN- & $-I D L D L$ & $18.7^{b}$ & $99 \%$ & 1392.6 & 1392.6 \\
\hline $2 \mathrm{~L}$ & CF-P9W5 & CF-GLN-p & -IDLDW & $14.0^{\circ}$ & $96 \%$ & 1545.4 & 1545.5 \\
\hline $2 \mathrm{La}$ & Cy3-P9W5 & Cy3-GLN-p) & -IDLDW & $19.6^{\circ}$ & $95 \%$ & 1626.8 & 1626.7 \\
\hline $4 \mathrm{~L}$ & CF-P9E4W5 & CF-GLN-p & -IDLEW & $13.9^{c}$ & $97 \%$ & 1559.1 & 1559.6 \\
\hline $5 \mathrm{~L}$ & CF-OP & $\mathrm{CF}-\mathrm{GLN}-\mathrm{E}_{2}$ & LP-IDLDW & $16.3^{e}$ & $97 \%$ & 1579.6 & 1579.5 \\
\hline
\end{tabular}

${ }^{a}$ All peptides were amidated at the C-terminus. Unlabeled peptides were acetylated at the $\mathrm{N}$-terminus. CF is 5(6)-carboxyfluorescein, Cy3 is Cyanine 3 carboxylic acid, and $\mathrm{F}_{2} \mathrm{Pmp}$ is the nondephosphorylatable $\mathrm{pY}$ mimic phosphonodifluoromethyl phenylalanine. The optimized peptides are highlighted in gray. ${ }^{*} \mathrm{RP}$-HPLC retention times $\left(R_{\mathrm{t}}\right)$ and purities were determined with a Phenomenex Kinetex XB-C18 column $(4.6 \mathrm{~mm} \times 100$ $\mathrm{mm}, 3.5 \mu \mathrm{m}, 100 \AA$ ), with mobile phases A (aqueous $0.05 \%$ TFA) and B (acetonitrile, $0.05 \%$ TFA), with the following elution conditions: ${ }^{a} 10-$ $40 \%$ B in $30 \mathrm{~min},{ }^{b} 20-50 \%$ B in $30 \mathrm{~min},{ }^{c} 20-60 \%$ B in $20 \mathrm{~min},{ }^{d} 10-95 \%$ B in $30 \mathrm{~min},{ }^{e} 5-95 \%$ B in $30 \mathrm{~min}$, and ${ }^{f} 5-65 \%$ B in $30 \mathrm{~min}$ Theoretical molecular weights are compared with those determined experimentally by ESI-MS spectrometry or high-resolution ESI-Q-Tof (for the optimized peptide OP and its precursor P8W5).
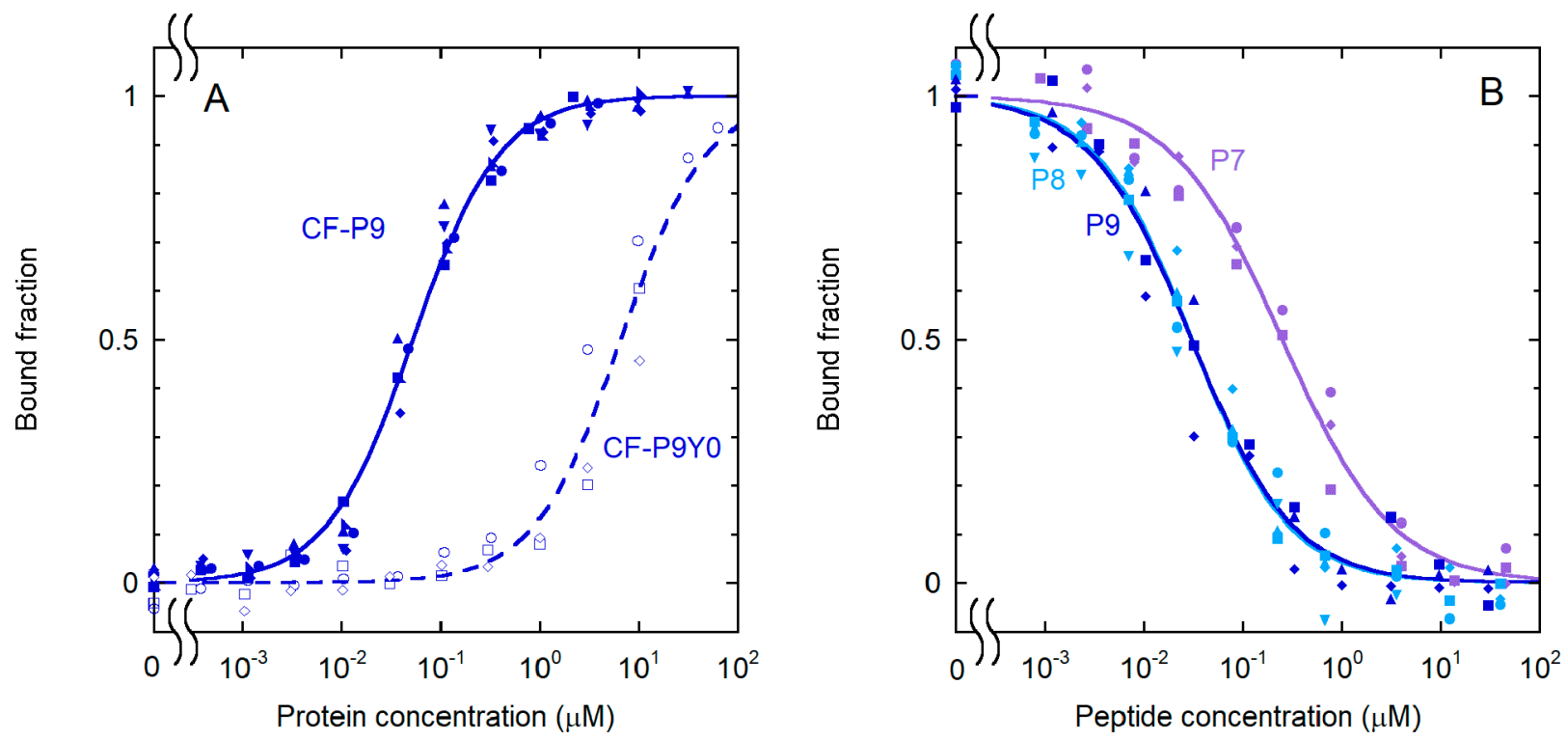

Figure 2. Effect of phosphorylation and sequence length on the binding of IRS-1 pY1172 peptides to the N-SH2 domain. (A) Binding curves for the phosphorylated and unphosphorylated sequence corresponding to the nine-residue region surrounding pY1172 of IRS-1 (see Table 1 for the sequences). The following experimental conditions were used: $1.0 \mathrm{nM} \mathrm{CF-P9}$ (filled symbols and solid lines) and $10 \mathrm{nM} \mathrm{CF-P9Y0} \mathrm{(empty} \mathrm{symbols}$ and dashed lines). (B) Displacement curves for unlabeled IRS-1 pY1172 analogues of different lengths [P9, P8, and P7 (see Table 1)]. A concentration of labeled peptide equal to $1.0 \mathrm{nM}$ CF-P9, interacting with the N-SH2 domain (40 nM N-SH2), was displaced with increasing amounts of the unlabeled peptides. The bound fraction of labeled peptide is reported as a function of the concentration of the competing, unlabeled peptide. The results of independent, replicate experiments ( $n=6$ for CF-P9, $n=4$ for P9 and P8, and $n=3$ for CF-P9Y0 and P7) are reported with different symbols and were fit collectively.

analogue CF-P9 (Table 1) was titrated with increasing concentrations of the $\mathrm{N}-\mathrm{SH} 2$ domain. The fraction of protein-bound peptide was determined from the increase in fluorescence anisotropy (Figure 2), and a $K_{\mathrm{d}}$ of $53 \pm 2 \mathrm{nM}$ was obtained (Table 2). 
Table 2. Dissociation Constants Obtained from the Fluorescence Anisotropy Binding Experiments ${ }^{a}$

\begin{tabular}{|c|c|c|c|c|c|c|c|}
\hline N. & Abbreviation & \multicolumn{2}{|c|}{ Sequence } & Domain/Protcin & \multicolumn{2}{|c|}{$K_{d}(\mathrm{nM})$} & \multirow{2}{*}{$\begin{array}{c}n \\
\text { (number of replicates) } \\
\frac{6}{6}\end{array}$} \\
\hline $1 \mathrm{~L}$ & CF-P9 & $\mathrm{CF}-\mathrm{GLN}-\mathrm{pY}$ & -IDLDL & $\mathrm{N}-\mathrm{SH} 2$ & 53 & $\pm \quad 2$ & \\
\hline $1 \mathrm{La}$ & CF-P9Y0 & CF-GLN- $Y$ & -IDLDL & N-SH2 & 6600 & \pm 600 & 3 \\
\hline \multirow[t]{2}{*}{$2 \mathrm{~L}$} & \multirow[t]{2}{*}{ CF-P9W5 } & \multirow[t]{2}{*}{$\mathrm{CF}-\mathrm{GLN}-\mathrm{pY}$} & \multirow[t]{2}{*}{-IDLDW } & N-SH2 & \multicolumn{2}{|c|}{$3.3 \pm 0.2$} & 4 \\
\hline & & & & C-SH2 & 4200 & \pm 300 & 3 \\
\hline $2 \mathrm{La}$ & Cy3-P9W5 & Cy3-GLN-pY & -IDLDW & N-SH2 & 23 & $\pm \quad 2$ & 3 \\
\hline $4 \mathrm{~L}$ & CF-P9E4W5 & $\mathrm{CF}-\mathrm{GLN}-\mathrm{pY}$ & -IDLEW & $\mathrm{N}-\mathrm{SH} 2$ & 8.2 & $\pm \quad 0.7$ & 3 \\
\hline \multirow[t]{10}{*}{$5 \mathrm{~L}$} & \multirow[t]{10}{*}{$\mathrm{CF}-\mathrm{OP}$} & \multirow{10}{*}{\multicolumn{2}{|c|}{$\mathrm{CF}-\mathrm{GLN}-\mathrm{F}_{2} \mathrm{Pmp}-\mathrm{IDLDW}$}} & N-SH2 & 68 & $\pm \quad 5$ & 3 \\
\hline & & & & C-SH2 & 39000 & \pm 4000 & 3 \\
\hline & & & & PTP & 10000 & \pm 800 & 2 \\
\hline & & & & SHP2 (wild-type) & 930 & $\pm \quad 70$ & 3 \\
\hline & & & & SHP2 (A72S) & 400 & \pm 40 & 2 \\
\hline & & & & SHP2 (E76V) & 330 & \pm 10 & 3 \\
\hline & & & & SHP2 (D61H) & 170 & \pm 10 & 2 \\
\hline & & & & SHP2 (D61G) & 150 & \pm 10 & 3 \\
\hline & & & & SHP2 (F71L) & 140 & $\pm \quad 10$ & 3 \\
\hline & & & & SHP2 (E76K) & 48 & \pm & 4 \\
\hline
\end{tabular}

${ }^{a}$ The dissociation constants and the associated errors are the results of collective fitting of independent, repeated experiments (as indicated in the number of replicates).

Phosphorylation Contributes Only $30 \%$ of the Standard Binding Free Energy. Association of $\mathrm{SH} 2$ domains with the partner proteins is regulated by phosphorylation, and therefore, the phosphate group is necessarily responsible for a large fraction of the binding affinity. At the same time, to have a good selectivity, the rest of the sequence must also contribute significantly to the peptide/protein interaction. To quantify this aspect, we performed a binding experiment (Figure 2A) with an unphosphorylated analogue of the labeled IRS-1 pY1172 peptide, CF-P9Y0 (Table 1). The affinity was approximately 100 times lower, with a $K_{\mathrm{d}}$ of $6.6 \pm 0.6 \mu \mathrm{M}$, compared with a $K_{\mathrm{d}}$ of $53 \pm 2 \mathrm{nM}$ for the phosphorylated peptide. The corresponding values for the standard free energy of binding (assuming a $1 \mathrm{M}$ standard state) are $-29.6 \pm 0.2$ and $-41.6 \pm 0.1 \mathrm{~kJ} / \mathrm{mol}$, respectively. Assuming additivity of contributions, the phosphate group is responsible for the difference of $-12.0 \pm 0.2 \mathrm{~kJ} / \mathrm{mol}$, i.e., for $<30 \%$ of the total standard binding free energy of the phosphorylated peptide. This result indicates that the contribution of the rest of the peptide predominates in the binding interactions and bodes well for our design efforts.

Sequence Optimization. The Phosphopeptide Sequence Can Be Reduced to Eight Amino Acids without a Loss of Affinity. Literature data are partially contradictory regarding the effect of shortening the IRS-1 pY1172 sequence on the binding affinity. $\mathrm{Kay}^{52}$ reported that the sequence could be shortened at the $\mathrm{C}$-terminus down to residue +5 and at the $\mathrm{N}$ terminus down to residue -2 , without any loss of affinity. By contrast, Case ${ }^{48}$ observed a significant decrease in affinity by shortening the sequence from SLN-pY-IDLDLVKD to LN-pYIDLDLV. Our previous study clearly indicated that residues -2 to +5 are the most important for the interaction. ${ }^{18}$ To clarify the role of $\mathrm{N}$-terminal residues in determining the $\mathrm{N}$ $\mathrm{SH} 2$ domain binding affinity, we performed displacement studies (Figure 2B) with the unlabeled peptide P9 and with the shortened analogues P8 and P7 (Table 1), where residues -3 or -2 and -3 were removed, respectively. No significant loss of affinity was observed by reducing the sequence to eight residues, while removal of the amino acid at position -2 caused a drastic perturbation of the complex stability (Figure 2B). The -2 to 5 IRS- 1 sequence is the minimal peptide with a nanomolar dissociation constant.

Single-Amino Acid Substitutions in the IRS-1 pY1172 Sequence Improve the $K_{d}$ to the Low Nanomolar Range. Hydrophobic residues are required at positions $+1,+3$, and +5 of the phosphopeptide sequence, ${ }^{18}$ but aromatic residues are present in some natural high-affinity binding sequences, at position +5 only. $8,10,48,53,54$ The crystallographic structures of some of these complexes ${ }^{8,10,24}$ show that an aromatic side chain can be accommodated by a relatively large hydrophobic pocket and that the peptide residue 5 interacts with the BG and EF loops of the domain, which are important for binding specificity. ${ }^{18,24}$ Finally, a preference for aromatic residues at position +5 has been indicated by several peptide library studies. $^{36,55-57}$

On the basis of these considerations, we predicted in silico the effect of different aromatic amino acids at position +5 . Free energy calculations indicated that substitution of $\mathrm{L}$ with the bulkier W (but not with F) could be favorable (Figure 3). The additional substitution of $\mathrm{D}$ at position +4 with the longer $\mathrm{E}$ was evaluated, as well, fora possible strengthening of the electrostatic interactions with the $\mathrm{KxK}$ motif in the BG loop. However, in this case no further increase in binding affinity was predicted by the free energy calculations (Figure 3). 


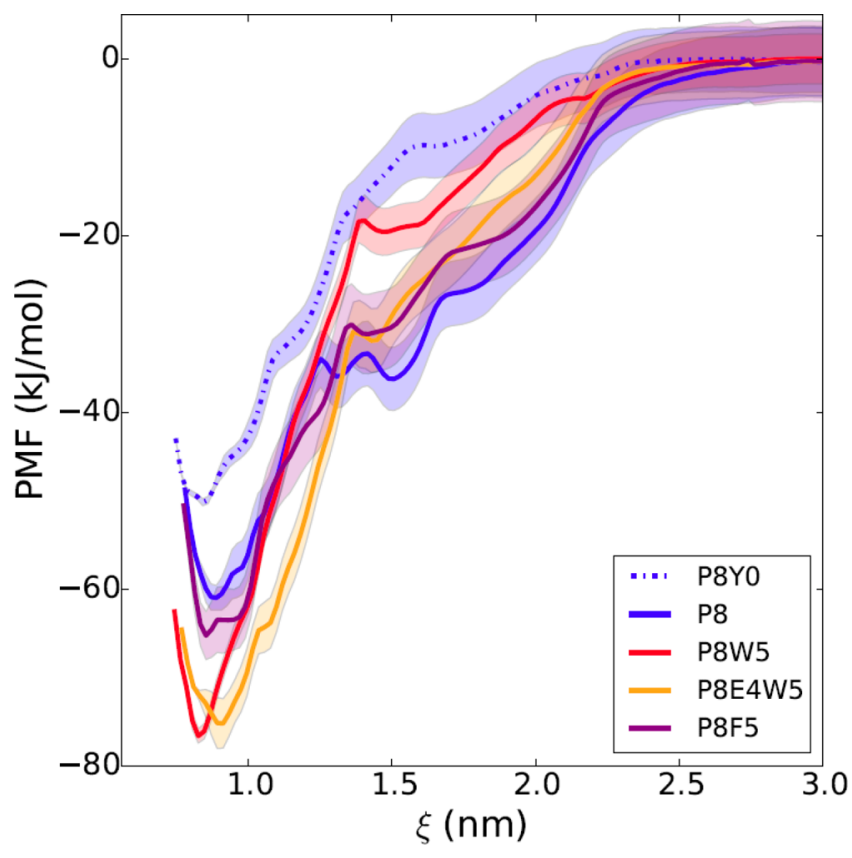

Figure 3. In silico free energy calculations for different modified sequences. The free energy profile is reported as a function of the distance between the centers of mass of the N-SH2 domain and the phosphopeptide. The simulations predict a loss of affinity of P8 (blue line) with dephosphorylation of the pY (dashed blue line; P8Y0 is the unphosphorylated analogue of P8) and a gain with substitution of $\mathrm{L}$ at position +5 with $\mathrm{W}$ (red line), but not with $\mathrm{F}$ (violet line). The additional substitution of $\mathrm{D}$ at position +4 with $\mathrm{E}$ (orange) does not provide any further increase in affinity. Shaded areas correspond to standard deviations in the PMF profile. For peptide sequences, see Table 1.
Analogues with $\mathrm{F}$ or $\mathrm{W}$ at position +5 (P8F5 or P8W5, respectively), as well as a labeled analogue with the $\mathrm{L}$ to $\mathrm{W}$ substitution (CF-P9W5) (Table 1), were synthesized and studied experimentally (Figure 4). As predicted, introduction of $\mathrm{W}$ at position +5 was highly favorable, leading to a decrease in the dissociation constant by one order of magnitude, for the labeled and unlabeled analogue (Tables 2 and 3). Consequently, the dissociation constant for the P8W5 analogue was $1.6 \pm 0.2 \mathrm{nM}$. By contrast, the additional $\mathrm{D}$ to $\mathrm{E}$ substitution resulted in a slight loss of binding affinity (Figure 4 and Tables 2 and 3 ).

On the basis of these results, further studies concentrating on the peptide with $\mathrm{W}$ at position +5 were conducted.

Binding Selectivity. The Modified Sequence Is Highly Selective for the N-SH2 Domain of SHP2. The selectivity of binding of CF-P9W5 was first assessed with respect to the C$\mathrm{SH} 2$ domain of SHP2 by fluorescence anisotropy (Figure S1). As reported in Table 2, the affinity for the $\mathrm{C}-\mathrm{SH} 2$ domain was almost 1000 times lower than that for the N-SH2 domain.

A more complete analysis of the binding selectivity was performed on a protein array considering 97 human $\mathrm{SH} 2$ domains (Figure 5). An analogue of CF-P9W5 was employed in this assay, where CF was substituted with the Cy3 dye, suitable for detection in the array reader. Control binding experiments showed that the change in fluorophore affected peptide binding affinity only marginally (Table 2 and Figure S2). Strikingly, significant binding was observed only with the $\mathrm{N}-\mathrm{SH} 2$ domain of SHP2 and, to a lesser extent, the $\mathrm{SH} 2$ domain of the adapter protein APS (also called SHP2B2). It is worth noting that binding to the N-SH2 domain of SHP1, which is the most identical to SHP2, ${ }^{17}$ was negligible.

Engineering Resistance to Degradation. Introduction of a Nonhydrolyzable pY Mimic Is Compatible with
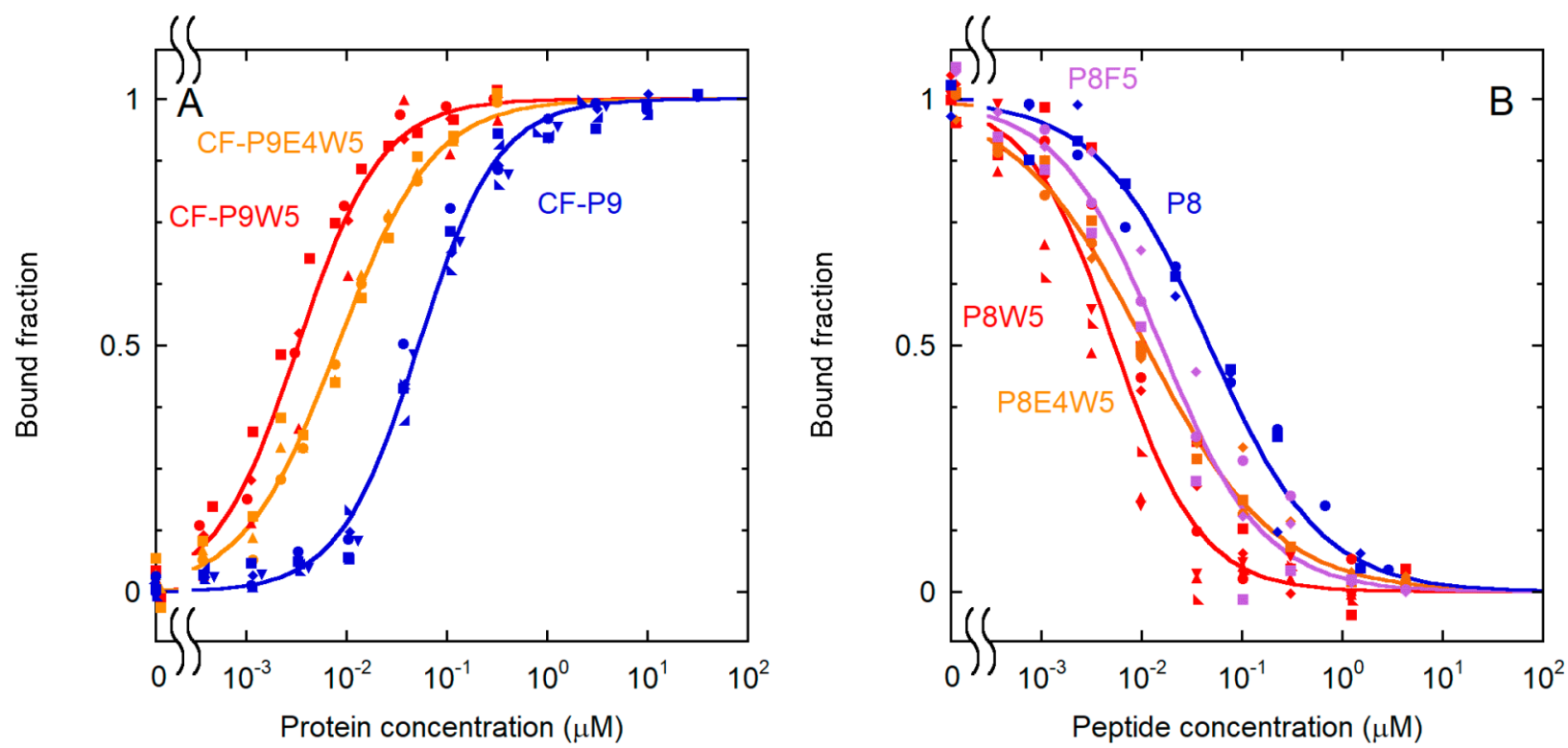

Figure 4. Effect of substitutions at position +5 on binding affinity. (A) Direct binding experiments with various analogues (for the peptide sequences, see Table 1). Substitution of L5 with $\mathrm{W}$ caused a dramatic increase in binding affinity, which was partially lost with the additional substitution of D4 with E. The following experimental conditions were used: $0.10 \mathrm{nM}$ CF-P9W5, $0.10 \mathrm{nM}$ CF-P9E4W5, and 1.0 nM CF-P9. Data for CF-P9 are repeated here for comparison. (B) Displacement assay, performed with various analogues (for the peptide sequences, see Table 1). A concentration of labeled peptide equal to $0.10 \mathrm{nM}$ CF-P9W5, interacting with the N-SH2 domain (3.3 nM N-SH2), was displaced with increasing amounts of the unlabeled peptides. The bound fraction of the labeled peptide is reported as a function of the concentration of the competing, unlabeled peptide. The results of independent, replicate experiments ( $n=5$ for CF-P9 and P8W5, $n=4$ for CF-P9W5, and $n=3$ for CF-P9E4W5, P8, P8F5, and P8E4W5) are reported with different symbols and were fit collectively. 
Table 3. Dissociation Constants Obtained from Displacement Experiments ${ }^{a}$

\begin{tabular}{|c|c|c|c|c|c|c|c|c|c|c|}
\hline N. & Abbreviation & \multicolumn{2}{|c|}{ Peptide sequence } & \multicolumn{3}{|c|}{$\mathrm{EC}_{50}(\mathrm{nM})$} & \multicolumn{3}{|c|}{$K_{d}^{u}(\mathrm{nM})$} & $\begin{array}{c}n \\
\text { (number of replicates) }\end{array}$ \\
\hline 1a & P8 & $\mathrm{LN}-\mathrm{pY}$ & -IDLDL & 47 & \pm & 4 & 22 & \pm & 3 & 3 \\
\hline 2 & P8W5 & $\mathrm{LN}-\mathrm{pY}$ & -IDLDW & 5.4 & \pm & 0.3 & & \pm & 0.2 & 5 \\
\hline 3 & P8F5 & $\mathrm{LN}-\mathrm{pY}$ & -IDLDF & 16 & \pm & 1 & 7 & \pm & 1 & 3 \\
\hline 4 & P8E4W5 & $\mathrm{LN}-\mathrm{pY}$ & -IDLEW & 11 & \pm & 1 & 4 & \pm & 1 & 3 \\
\hline 5 & $\mathrm{OP}$ & $\mathrm{GLN}-\mathrm{F}_{2} \mathrm{P}$ & -IDLDW & 32 & \pm & 5 & 15 & \pm & 3 & 4 \\
\hline
\end{tabular}

${ }^{a}$ All measurements were performed on the N-SH2 domain of SHP2. Experiments were performed at $3.3 \mathrm{nM} \mathrm{N}-\mathrm{SH} 2$ and $0.5 \mathrm{nM}$ CF-P9W5 (for P8 and OP) or $0.1 \mathrm{nM} \mathrm{CF-P9W5} \mathrm{(for} \mathrm{the} \mathrm{other} \mathrm{peptides).} \mathrm{EC}_{50}$ indicates the concentration needed to displace half of the labeled peptides, while $K_{\mathrm{d}}^{\mathrm{u}}$ is the dissociation constant of the unlabeled peptide (see the Supporting Information). $\mathrm{EC}_{50}$ values and the associated errors are the results of collective fitting of independent, repeated experiments (as indicated in the number of replicates).

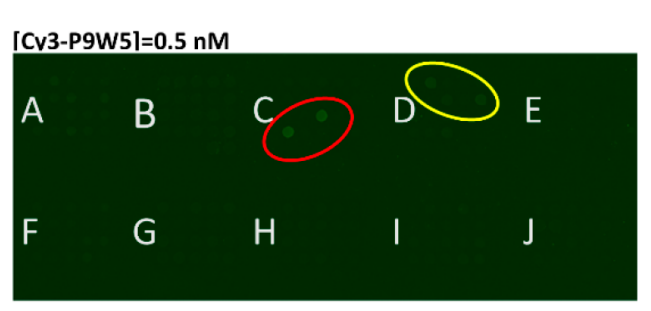

Protein loading control (anti-GST antibody signal)
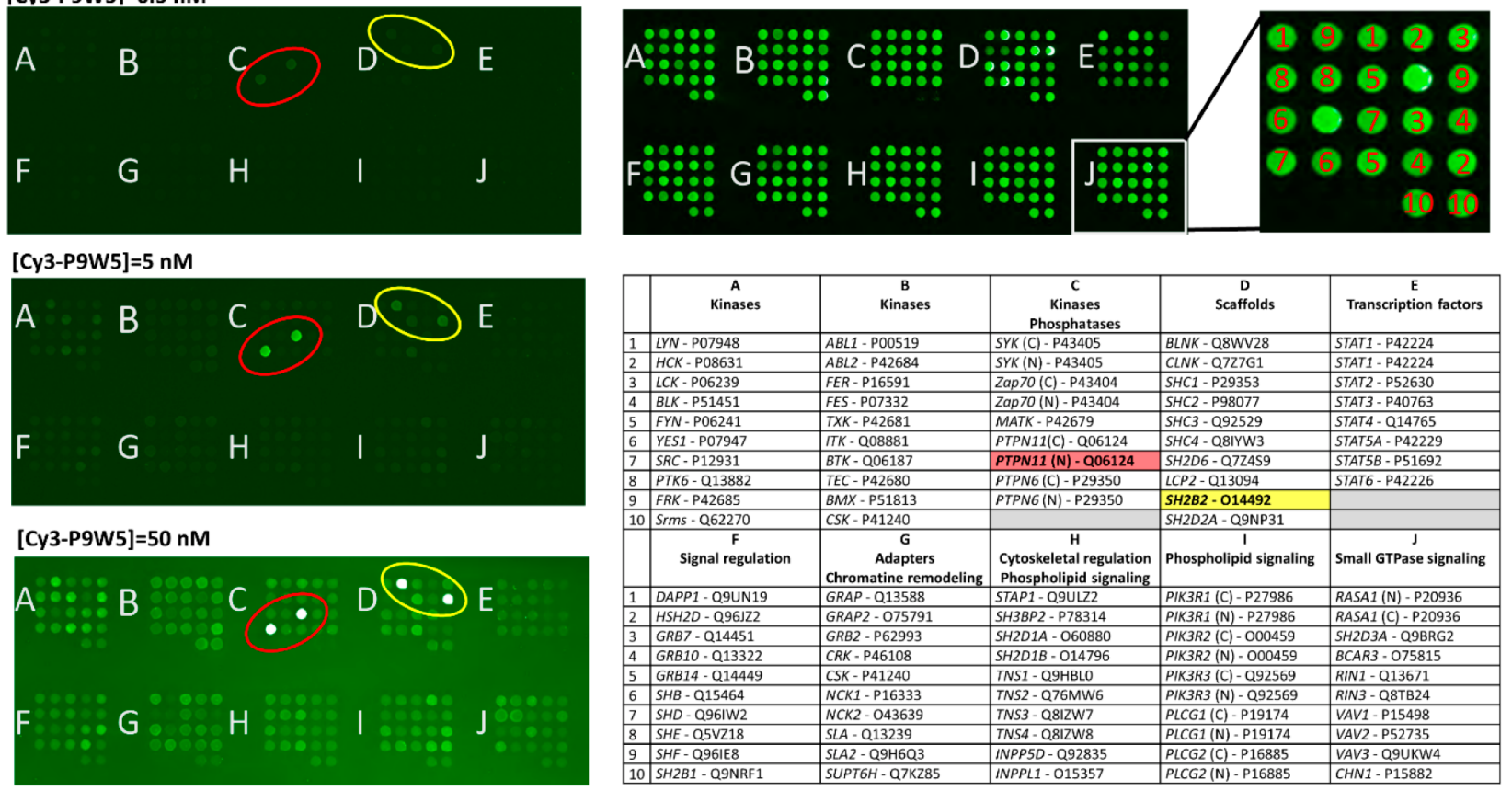

Figure 5. Binding selectivity of Cy3-P9W5 for an array of SH2 domains. In the left panels, the fluorescently labeled analogue Cy3-P9W5 was allowed to interact with an array of human SH2 domains, expressed and purified as glutathione $S$-transferase (GST) fusion constructs. Binding affinity was assessed by the fluorescence of the bound peptide, at concentrations of $0.5 \mathrm{nM}$ (top), $5.0 \mathrm{nM}$ (center), and $50 \mathrm{nM}$ (bottom). Each SH2 domain was spotted in duplicate, and negative control spots (with GST only) are also present. The bright spots correspond to the N-SH2 domain of SHP2 (circled in red) and to the SH2 domain of the SH2 and PH domain-containing adapter protein APS (also called SHP2B2, circled in yellow). The intensity of all other spots is comparable to that of the negative controls. The right panels shows a control of the protein loading in each spot, performed with an anti-GST antibody (top), and the position of each SH2 domain in the array (bottom). For each SH2 domain, the gene name and Uniprot codes are reported. Each domain was spotted in duplicate.

Nanomolar Binding Affinity. For intracellular or in vivo applications of the phosphopeptide, it is essential to make it resistant to degradation. The most labile moiety is the phosphate group of the $\mathrm{pY}$ residue, which can be hydrolyzed by protein tyrosine phosphatase, possibly also including SHP2, of which IRS-1 pY1172 has been shown to be a substrate. ${ }^{58}$ We substituted the pY with the nonhydrolyzable mimetic phosphonodifluoromethyl phenylalanine $\left(\mathrm{F}_{2} \mathrm{Pmp}\right)$, which is isosteric with $\mathrm{pY}$ and has a total negative charge comparable to that of $\mathrm{pY}$ under physiologic $\mathrm{pH}$ conditions. ${ }^{43,59}$

Binding experiments demonstrated that the substituted analogue [CF-OP, for the optimized peptide (Table 1)] has a dissociation constant for the $\mathrm{N}-\mathrm{SH} 2$ domain that is just one order of magnitude worse with respect to that of CF-P9W5
$(68 \pm 5 \mathrm{nM}$ vs $3.3 \pm 0.2 \mathrm{nM})$ (Figure S3 and Table 2). Similarly, the dissociation constant for the unlabeled peptide OP was $15 \pm 3 \mathrm{nM}(1.6 \pm 0.2 \mathrm{nM}$ for P8W5 $)$ and thus remained in the nanomolar range (Table 3 ). Binding experiments with the $\mathrm{C}-\mathrm{SH} 2$ domain confirmed that the optimized peptide maintained the selectivity of the parent sequence (Figure S3 and Table 3).

The Optimized Peptide OP Is Resistant to Proteolytic Degradation. To test resistance to proteases, the optimized peptide OP and P8W5 were incubated in human serum for 24 $\mathrm{h}$ and then analyzed by HPLC. Both peptides were degraded by $<50 \%$ after 1 day. By comparison, the decapeptide XP (WFKYYGKAIY, with free termini), ${ }^{60}$ which we used as a positive control, was totally degraded in $3 \mathrm{~h}$ (Figure S4). 

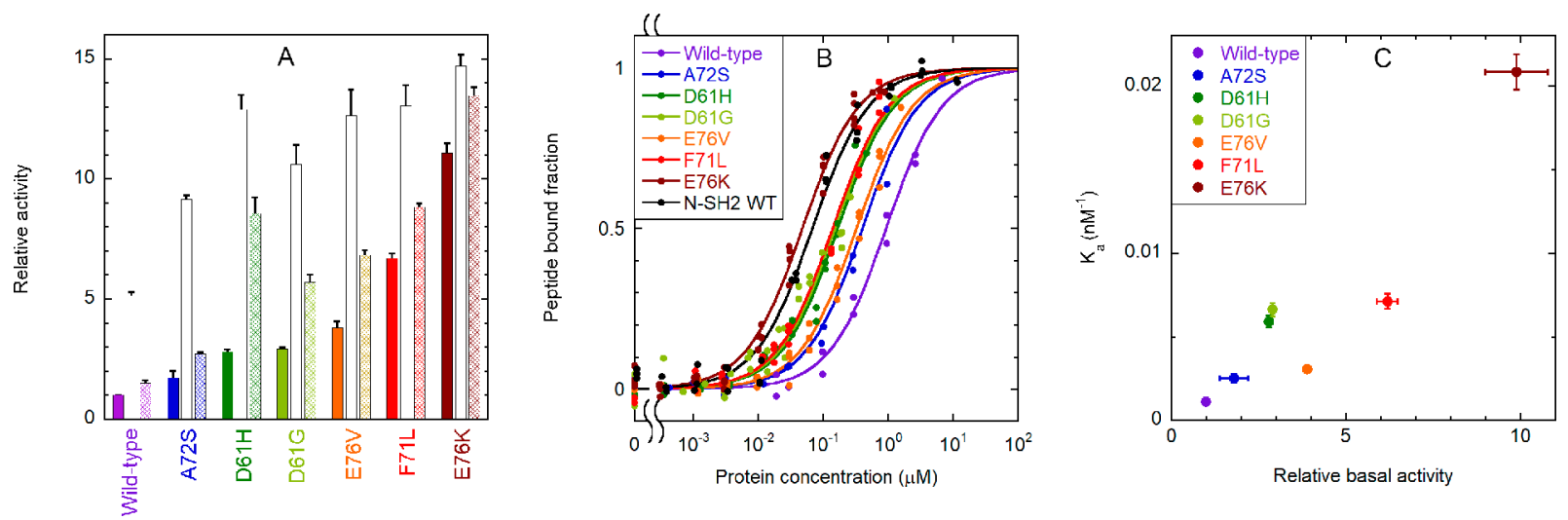

Figure 6. Binding of the CF-OP peptide to the whole SHP2 protein (wild type and pathogenic mutants) and activation of the phosphatase activity. (A) Relative catalytic activity of the wild-type protein and selected pathogenic mutants, under basal conditions (filled bars) and after stimulation with $10 \mu \mathrm{M}$ BTAM peptide (empty bars) or $10 \mu \mathrm{M}$ OP (dashed bars). All values were normalized to the basal activity of the wild-type protein. Each experiment was performed in triplicate. Binding to phosphorylated sequences induces activation. All mutations cause an increase in basal activity by destabilizing the autoinhibited conformation, and a concomitant enhanced responsiveness to activating phosphopeptides. (B) Curves for binding of the CF-OP peptide to the wild-type protein and selected mutants, obtained from fluorescence anisotropy experiments (1.0 nM CF-OP). Independent replicate experiments $(n=4$ for E76K, $n=3$ for E76V, F71L, D61G, and wild-type N-SH2, and $n=2$ for the wild type, A72S, D61H) were fitted collectively. (C) Correlation between the relative basal activity of the various mutants (as reported in panel A) and their binding affinity (association constant, i.e., $1 / K_{\mathrm{d}}$ ) for CF-OP. An enhanced basal activation of the protein, caused by destabilization of the autoinhibited state, is accompanied by an increased affinity for the CF-OP peptide. Therefore, CF-OP binds more tightly to the most activating mutants, which also cause the strongest pathogenic effects. Error bars represent standard deviations.

Similarly, OP was stable in DMEM for 3 days (data not shown). These results are probably due to the presence of the $\mathrm{pY}$ or $\mathrm{F}_{2} \mathrm{Pmp}$ residues and to the protected termini, and they bode well for potential in vivo applications of the peptides.

Binding to and Activation of the SHP2 Protein. Pathogenic Mutants Bind to Phosphopeptides with an Affinity Much Higher Than That of the Wild-Type Protein. As discussed in the Introduction, we and others have hypothesized that, in its autoinhibited state, the conformation of the $\mathrm{N}$ $\mathrm{SH} 2$ domain prevents efficient association with binding partners, while the affinity of SHP2 for phosphorylated sequences is maximized in the open, active state. ${ }^{19,21-23}$ This model has many relevant consequences, because it implies that pathogenic mutants have a twofold effect: they increase the activity of the phosphatase but also its affinity for binding partners. In principle, both effects could be the origin of the hyperactivation of the signal transduction pathways involved in the pathologies caused by PTPN11 mutations.

Notwithstanding the relevance of this aspect, to the best of our knowledge, no direct phosphopeptide binding experiments with whole SHP2 protein have ever been performed, possibly due to the fact that $\mathrm{pY}$ can be dephosphorylated by the PTP domain (see the next section). Now, OP and its fluorescent analogue CF-OP allow us to directly assess the hypothesis described above. Figure 6 and Table 2 report the results of binding experiments performed with CF-OP and wild-type SHP2 or the pathogenic mutants A72S, E76K, D61H, D61G, F71L, and E76V. E76K is among the most common somatic lesions associated with leukemia and has never been observed as a germline event in individuals with NS, ${ }^{3,20}$ as it results in early embryonic lethality. ${ }^{61}$ This variant is strongly activating, with the basal activity of the corresponding mutant being at least 10 times higher than that of the wild-type protein. Conversely, A72S is a germline mutation specifically recurring among subjects with NS. In this case, basal activation is only twofold. ${ }^{21}$ In humans, the D61G substitution has been found in both NS and leukemia, ${ }^{62}$ and in animal models, it induces both NS-like features and myeloproliferative disease. ${ }^{63}$ The D61H, F71L, and E76V amino acid substitutions have been identified as somatic events in JMML and other leukemias, ${ }^{3}$ and when transmitted in the germline, they are associated with a high prenatal lethality (M. Zenker, personal communication, September 2019). Interestingly, we observed that the affinity for CF-OP nicely parallels the basal activity of these mutants (Figure 6). This finding provides a first direct confirmation that the the affinity of SHP2 for phosphorylated binding partners is higher in the open, active conformation than in the closed, autoinhibited state.

OP Is Also an Inhibitor of the PTP Domain. On the basis of previous reports of the dephosphorylation of IRS-1 pY1172 by SHP2, ${ }^{58}$ we verified if $\mathrm{P} 8$ and P8W5 are also substrates of this protein. These experiments were performed with a truncated SHP2 construct lacking the N-SH2 domain $\left(\mathrm{SHP}_{\Delta 104}\right)$, as it is fully activated and was shown to be more stable and less prone to aggregation than the isolated PTP domain. ${ }^{37}$ As reported in Figure S5, dephosphorylation was indeed observed, although to a lesser extent than for other phosphopeptides. Using the nondephosphorylatable peptide CF-OP, we measured directly binding to the PTP domain of SHP2 (Figure S6 and Table 2). Significant association was observed, although with a much lower affinity than with the N-SH2 domain $\left(K_{d}=10.0 \pm 0.8\right.$ $\mu \mathrm{M})$.

These findings indicate that, in principle, the nondephosphorylatable OP could act as a double-hit SHP2 inhibitor, acting on both PPIs and catalytic activity. In addition, they underline the importance of substituting $\mathrm{pY}$ with a nondephosphorylatable mimic: in principle, any highaffinity phosphopeptide ligand of the $\mathrm{N}-\mathrm{SH} 2$ domain (including natural sequences) could be used to inhibit association of SHP2 with its binding partners, but these sequences could be dephosphorylated by SHP2 itself, losing their binding affinity.

OP Activates SHP2 Only Weakly. Binding of mono- or bisphosphorylated peptides causes activation of SHP2. We 

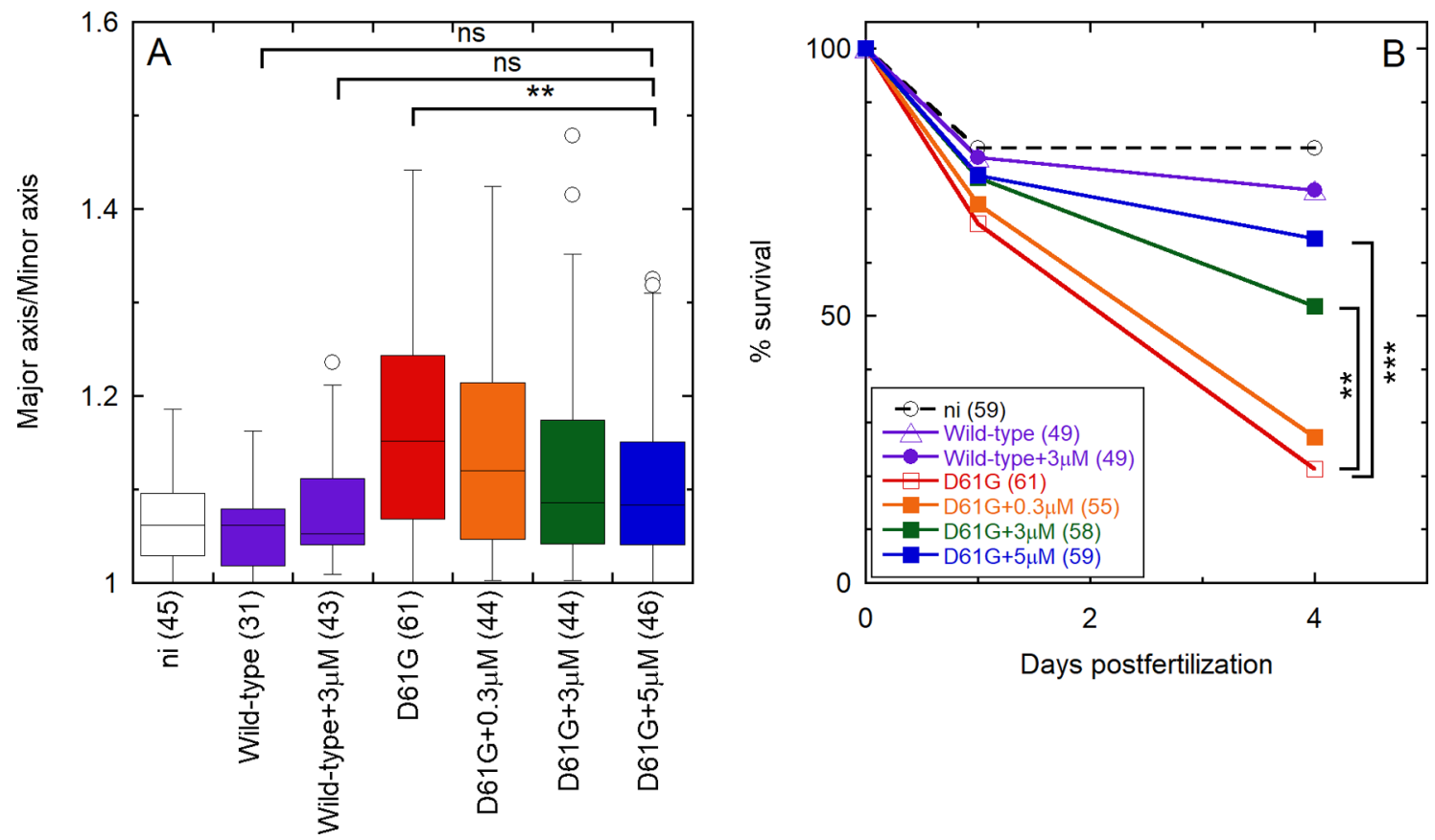

Figure 7. OP partially rescues D61G Shp2a-induced gastrulation defects and mortality in a dose-dependent manner in zebrafish embryos. Embryos were injected at the one-cell stage with mRNA encoding GFP-2A-Shp2-D61G or GFP-Shp2-wild-type with or without the peptide at concentrations of $0.3,3$, and $5 \mu \mathrm{M}$. Non-injected embryos (ni) were evaluated as a control. (A) Ovality of embryos 11 hpf, as indicated by the ratio of the long and short axis. Tukey's honest significant difference test was performed to assess significance. In the box plot, the horizontal line indicates the median, box limits indicate the $25^{\text {th }}$ and $75^{\text {th }}$ percentiles (interquartile range), and whiskers (error bars) extend to the maximum and minimum values, or to 1.5 times the interquartile range from the $25^{\text {th }}$ and $75^{\text {th }}$ percentiles, if some data points fall outside this range. In the latter case, outliers are indicated as single data points. (B) Embryo lethality. Surviving embryos were counted 1 and 4 days post fertilization. Survival was plotted, and a log rank test was performed to access differences between groups. Nonsignificant (n.s.), $p>0.05$; $* p<0.05$; $* *<0.01$; $* * *<<$ 0.001 . The numbers of embryos that were analyzed in each case are indicated in parentheses, in the axis labels (A), or in the legend (B) and ranged from 31 to 61 .

tested the effect of OP on the wild-type and mutated proteins. As shown in Figure 6, activation was generally weak, compared with that induced by the bisphosphorylated BTAM peptide. Interestingly, under the experimental conditions used $(10 \mu \mathrm{M}$ peptide), the $\mathrm{N}-\mathrm{SH} 2$ domain of the wild-type and mutant proteins is nearly saturated by the OP, according to the binding experiments reported in Figure 6. This finding indicates that the peptide could inhibit SHP2 PPIs, causing only a limited increase in catalytic activity. In any case, as demonstrated by studies of truncated constructs lacking the $\mathrm{N}$ $\mathrm{SH} 2$ domain, ${ }^{2,9,38}$ activation of SHP2 without proper PPIs has no pathogenic effects.

OP Reverses the Effects of D61G Mutation In Vivo. We used the zebrafish model system to explore the in vivo effect of the peptide. Zebrafish Shp2a is highly homologous to human SHP2 (91.2\% protein sequence identity); in particular, the sequences of the $\mathrm{N}-\mathrm{SH} 2$ domain and the $\mathrm{N}-\mathrm{SH} 2 / \mathrm{PTP}$ interface are identical in the human and fish proteins. RASopathy-associated mutants, including activating mutants of Shp2a, greatly impact zebrafish development. Microinjection of synthetic mRNA encoding NS-associated mutants of Shp2 at the one-cell stage induces NS-like traits. ${ }^{64}$ During gastrulation, convergence and extension movement are affected, resulting in oval-shaped embryos, with an increased major/minor axis length ratio $11 \mathrm{~h}$ postfertilization (hpf). ${ }^{64}$ Here we co-injected Shp2a-D61G mRNA with OP in zebrafish embryos to investigate whether OP rescues the defective cell movements during gastrulation.
As shown in Figure 7 and Figure S7, we observed a dosedependent decrease in Shp2a-D61G-induced major/minor axis ratios, with a rescue of the phenotype that was significant at a peptide concentration of $5 \mu \mathrm{M}$. On the contrary, embryos injected with wild-type Shp2a were almost perfect spheres at $11 \mathrm{hpf}$, and co-injection with $3 \mu \mathrm{M}$ peptide had no impact on their shape. As expected, a large portion of D61G Shp2ainjected embryos were severely affected and died during embryonic development, whereas injection of wild-type Shp2a did not induce significant lethality. We followed the survival of D61G Shp2a-injected embryos and observed a significant and dose-dependent improvement in the survival of embryos upon co-injection with $0.3,3$, and $5 \mu \mathrm{M}$ OP (Figure $7 \mathrm{~B}$ ). By contrast, the lethality of wild-type Shp2a embryos was not affected by co-injection of $3 \mu \mathrm{M}$ OP. Altogether, these results indicate that co-injection of the OP rescued the developmental defects induced by a pathogenic, basally activated Shp2a variant, while it had no effect on wild-type embryos.

\section{DISCUSSION}

Here, we developed peptide-based molecules with nanomolar affinity for the N-SH2 of SHP2, good selectivity, stability to degradation, and an affinity for pathogenic variants of SHP2 up to 20 times higher than for the wild-type protein, as a novel strategy for targeting upregulated SHP2 function. Our findings also provide several insights into the interaction of phosphopeptides with $\mathrm{SH} 2$ domains and, in particular, with the N-SH2 domain of SHP2 and into the suitability of these recognition units as therapeutic targets. 
Soon after their discovery, the affinities of $\mathrm{SH} 2$ domains for their binding partners (i.e., the dissociation constants) were considered to fall in the range of $10-100 \mathrm{nM} .{ }^{65}$ However, it turned out that most of the binding studies performed in that period were affected by experimental artifacts, leading to an overestimation of the binding affinities. ${ }^{44,50} \mathrm{~A}$ reassessment of the affinity values led to a commonly accepted range on the order of $0.1-10 \mu \mathrm{M}^{42,44-46}$ Such moderate affinities are considered to be crucial for allowing transient association and dissociation events in cell signaling. Consistently, $\mathrm{SH} 2$ domains artificially engineered to reach low nanomolar affinities for phosphorylated sequences (known as superbinders), ${ }^{66}$ by increasing the affinity of the domain for the $\mathrm{pY}$ residue, have detrimental consequences for signal transduction. However, micromolar binding affinities make $\mathrm{SH} 2$ domains in general less than optimal therapeutic targets.

In the case of the N-SH2 domain of SHP2, literature results on the affinity for the IRS-1 pY1172 peptide were contradictory, with dissociation constants varying by 3 orders of magnitude. ${ }^{19,48,49}$ Here, we showed that, at least for this peptide, the dissociation constant is in the nanomolar range. For the N-SH2 domain, similar affinities have been reported also for GRB2-associated binding protein 1 (Gab1), pY627, ${ }^{67}$ and Gab2, pY614, ${ }^{54}$ and several other peptides have dissociation constants within one order of magnitude of that of IRS-1 pY1172. ${ }^{8,17}$ In addition, in the study presented here, we were able to further improve the affinity with respect to the parent peptide. Therefore, the N-SH2 domain of SHP2 might constitute an exception in the panorama of $\mathrm{SH} 2$ domains, regarding binding affinity. In most cases, interaction of phosphopeptides with $\mathrm{SH} 2$ domains is dominated by the hydrophobic effect (except for the pY pocket). However, the $\mathrm{N}-\mathrm{SH} 2$ domain of SHP2 has a peculiar KxK motif in the region of the BG loop pointing toward the binding groove, which can interact electrostatically with acidic residues present in the peptide sequence at positions +2 and $+4 .{ }^{18}$ Therefore, by contrast to the superbinders, the high binding affinity of the $\mathrm{N}$ $\mathrm{SH} 2$ domain is a result of additional interactions in the selectivity-determining region, and not in the pY pocket. Indeed, our data showed that the pY phosphate contributed $<30 \%$ of the standard binding free energy. This finding is comparable to what has been reported for other SH2 domains. $^{68}$

Our results also showed that residue -2 contributes significantly to the binding affinity. Indeed, while the specificity of most $\mathrm{SH} 2$ domains is determined by residues $\mathrm{C}$-terminal to the $\mathrm{pY}$, peptide library and array studies have shown that, contrary to most other $\mathrm{SH} 2$ domains, the $\mathrm{N}-\mathrm{SH} 2$ domain of SHP2 has specific preferences for position $-2 .^{18}$ This peculiarity is due to the fact that, in place of the commonly conserved arginine at position 2 in the first $\alpha$-helix $(\alpha \mathrm{A} 2)$, the $\mathrm{N}-\mathrm{SH} 2$ domain of SHP2 has G13. Consequently, a hydrophobic peptide residue at position -2 can insert in the space left free by the missing protein side chain and interact with V14 $\alpha \mathrm{A} 3$ and with the phenol ring of $\mathrm{pY}$, stabilizing its orientation and the overall complex. ${ }^{18}$

A preference of the N-SH2 domain of SHP2 for hydrophobic residues at positions $+1,+3$, and +5 is well-established. These side chains insert into the groove on the surface of the domain and interact with exposed hydrophobic patches. ${ }^{18}$ Now our data demonstrate that the bulky, aromatic side chain of tryptophan at position +5 is 10 times better (in terms of dissociation constant) than the leucine residue, which is present in high-affinity natural sequences such as those of IRS1, Gab1, and Gab2. Overall, these data confirm that the phosphopeptide sequence in the -2 to +5 stretch contributes significantly to the binding affinity. In principle, highly specific binding should be possible.

In general, $\mathrm{SH} 2$ domains are only moderately discriminating for binding target sequences, and a range of residues is tolerated at each site. ${ }^{44,68}$ Consequently, nonspecific tyrosinephosphorylated sequences are usually bound only 10-100-fold more weakly than specific targets. ${ }^{42,45,68,69}$ Indeed, additional specificity is often provided by tandem SH2 domains: ${ }^{68}$ two closely spaced tyrosine-phosphorylated motifs bind to tandem $\mathrm{SH} 2$ domains with 20-50-fold greater affinity and specificity compared with the binding of a single $\mathrm{SH} 2$ domain with a single tyrosine-phosphorylated motif. ${ }^{45}$ SHP2 and its $\mathrm{SH} 2$ domains are no exception in this case, as peptide library and array studies, together with the sequences of known natural binding partners, showed a significant variability in the sequences of peptides bound by SHP2. ${ }^{18}$ However, our results indicate that some peptides (like those developed here) can bind specifically to a single SH2 domain. Among an array of 97 human SH2 domains, we found some interference only with adapter protein APS (also called SHP2B2). The structure of the APS SH2 domain in complex with a cognate protein shows that the phosphorylated sequence binds in a folded, kinked conformation, rather than in the usual extended binding mode. ${ }^{70}$ This observation should facilitate the further development of our peptides, to avoid the unwanted interaction with APS, without affecting the affinity for the target N-SH2.

Finally, it is worth mentioning that approximately one order of magnitude in affinity was lost by substituting the pY residue with the nondephosphorylatable mimic $\mathrm{F}_{2} \mathrm{Pmp}$. This finding is consistent with previous studies showing that $\mathrm{F}_{2} \mathrm{Pmp}$ is tolerated differently by various $\mathrm{SH} 2$ domains, and its insertion in place of $\mathrm{pY}$ in a phosphopeptide sequence can lead either to a loss or to an increase in affinity, by approximately one order of magnitude. ${ }^{59}$ Further optimization of this aspect is warranted, but the dissociation constant of our nondephosphorylatable peptide remained in the nanomolar range.

The nondephosphorylatable peptide allowed novel experiments on several aspects of SHP2 function and regulation, previously complicated by the fact that many phosphorylated sequences that bind to the $\mathrm{N}-\mathrm{SH} 2$ domain are also substrates of the PTP catalytic site. Examples include IRS-1, ${ }^{49,58}$ Gab1, ${ }^{71,72}$ Gab2, ${ }^{73}$ PDGFR, ${ }^{74,75}$ PD- $1,{ }^{8}$ and SHPS-1. ${ }^{76,77}$ The OP, developed here, avoids the practical difficulty of dephosphorylation by SHP2 itself during the experiments.

As discussed in the Introduction, in the autoinhibited state of SHP2, the N-SH2 binding groove is closed, apparently making phosphopeptide association impossible. By contrast, the $\mathrm{N}-\mathrm{SH} 2$ binding site is open in the structure of the isolated $\mathrm{N}-\mathrm{SH} 2$ domain or of active SHP2. Consequently, it has been hypothesized that mutations destabilizing the closed state and favoring SHP2 activation could lead to an increase in binding affinity. ${ }^{21}$ This idea is indirectly supported by the fact that basally activated mutants require lower concentrations of $\mathrm{SH} 2$ domain binding phosphopeptides to reach full activation. ${ }^{19,21-23}$ However, no direct measurements of the binding of the phosphopeptide to different SHP2 variants had been reported until now. Our data directly demonstrate that the affinity for phosphopeptides of activated variants of SHP2 can increase by a factor of 20 , reaching the same value as that of the isolated domain in the most active mutants. This 
consequence of pathogenic mutations adds to the increase in basal activity and might be the main factor responsible for hyperactivation of signaling pathways modulated by SHP2. Interestingly, for possible therapeutic applications, in a cellular environment, N-SH2 targeting peptides, such as those developed here, would act as effective inhibitors of the PPIs of mutant, hyperactivated SHP2, while they would have a much weaker effect on the wild-type protein. This behavior is the exact opposite of what has been observed for allosteric inhibitors, such as SHP099, which have significantly impaired activity in pathogenic variants of SHP2. ${ }^{23,25}$

A second link between SHP2 activity and binding functions is provided by the fact that SHP2 interactors are both ligands of the $\mathrm{SH} 2$ domains and substrates of the catalytic PTP domain, often with the same phosphorylated sequence. We showed here that our modified sequence can be dephosphorylated, too, when it comprises a normal pY residue. These data indicate the possible presence of a still uncharacterized feedback mechanism for regulating SHP2 signaling. Using our nondephosphorylatable peptide, we could demonstrate that a N-SH2 binding sequence associates with the catalytic PTP domain, too, although with a lower affinity. This finding suggests that it might be possible to develop double-edged sword molecules, which can inhibit both the catalytic activity and the PPIs of SHP2.

Phosphorylated sequences cause SHP2 activation by binding to the N-SH2 domain and inducing or stabilizing a domain conformation that is incompatible with the N-SH2/PTP interaction. In principle, it is possible that different phosphopeptide sequences do not have the same aptitude for causing or favoring the conformational transition of the $\mathrm{N}$ $\mathrm{SH} 2$ domain needed for SHP2 activation. In this case, the binding affinity and activating potential of phosphopeptides would not be strictly coupled. Some literature data indicate that this might be the case. For instance, the sequences corresponding to pY546, pY895, and pY1222 of IRS-1 (rat ortholog numbering $)^{48,49}$ or artificial sequences AALN-pYAQLMFP and AALN-pY-AQLWYA ${ }^{56}$ have similar dissociation constants for the N-SH2 domain (within a factor of 2), but the concentrations of these phosphopeptides needed for full activation of SHP2 differ by orders of magnitude. The interpretation of these studies is complicated by the fact that in principle these sequences could be dephosphorylated by SHP2, to different extents, during the activation experiments. Our data show that a concentration of the nonhydrolyzable phosphopeptide that almost completely saturates the N-SH2 domain causes only partial activation. While the inability of this specific sequence to favor activation cannot be ruled out, it is possible that partial activation is caused by inhibition of SHP2 activity due to association of the peptide with the PTP domain. In any case, even if activation of SHP2 without proper PPIs is inconsequential, ${ }^{2,9,38}$ it is important to note that the molecules developed here can inhibit the association of SHP2 with its partners, without causing complete activation, particularly for the wild-type protein.

Inhibition of PPIs, particularly using peptides, is currently a hot area of pharmaceutical research. For the RAS/MAPK pathway alone, at least 30 inhibitors of PPI have been developed, and several of them are undergoing clinical trials. ${ }^{78}$ However, no studies of this type have been reported in the case of SHP2, notwithstanding the central role of this phosphatase in the pathway. Peptides are particularly appealing for the inhibition of PPIs, where large interfaces are involved, which are difficultly targeted selectively by small molecules. An increasing number of drugs based on peptides or peptidomimetics is progressing in the drug development pipeline. ${ }^{79}$ Possible challenges in the therapeutic applications of peptidebased molecules are their rapid degradation and poor cell uptake, particularly for highly charged sequences. ${ }^{79}$ Here we successfully overcame the first hurdle, thanks to the introduction of non-natural amino acids. With regard to the second issue, several studies have demonstrated that efficient intracellular delivery of phosphopeptide mimics is possible, for instance, by conjugation to cell-penetrating sequences. ${ }^{40,80-83}$

Our in vivo findings on zebrafish embryos are very promising in light of potential applications, particularly considering that $\mathrm{N}-\mathrm{SH} 2$ targeting peptides are more effective on activating mutants than on the wild-type protein, contrary to allosteric inhibitors such as SHP099. ${ }^{23,25}$ Indeed, in addition to their possible use as a research tool to study the role of PPIs in the function of SHP2, and regulation of the pathways controlled by this protein, including RAS/MAPK and PI3K/AKT signaling, the reported peptides constitute lead compounds for the development of new drugs against malignancies driven by PTPN11 mutations, such as JMML, AMoL, and ALL, also considering that allosteric inhibitors have low activity against basally activated SHP2 variants. ${ }^{23,25}$ Finally, another possible field of therapeutic application is represented by rare diseases such as NS and NSML, which are caused by activating mutations of PTPN11 (against which the available allosteric inhibitors are poorly active) and cause several severe postnatal, evolutive clinical manifestations, particularly hypertrophic cardiomyopathy. ${ }^{15}$

\section{EXPERIMENTAL SECTION}

Materials. Fmoc (9-fluorenylmethyloxycarbonyl)-amino acids were obtained from Novabiochem (Merck Biosciences, La Jolla, CA). Rink amide MBHA resin (0.65 mmol/g, 100-200 mesh) was purchased from Novabiochem. All other protected amino acids, reagents, and solvents for peptide synthesis were supplied by SigmaAldrich (St. Louis, MO). The LB medium components, all of the reagents used to prepare the buffers, and the Bradford reagent were purchased from Sigma-Aldrich. Tris(2-carboxyethyl)phosphine (TCEP) was obtained from Soltec Ventures (Beverly, MA). Spectroscopic grade organic solvents were purchased from Carlo Erba Reagenti (Milan, Italy). Cell culture medium growth factors and antibodies were purchased from VWR International PBI (Milan, Italy), EuroClone (Milan, Italy), Promega (Madison, WI), Invitrogen (Carlsbad, CA), Cell Signaling (Danvers, MA), Sigma-Aldrich, and Santa Cruz Biotechnology (Dallas, TX).

Peptide Synthesis. The solid-phase peptide synthesis of the analogues described herein was performed on the Rink Amide MBHA resin, using standard Fmoc chemistry protocols. The phosphorylated amino acids Fmoc-Tyr $(\mathrm{PO}(\mathrm{OBzl}) \mathrm{OH})-\mathrm{OH}$ and Fmoc-Phe$\left(\mathrm{CF}_{2} \mathrm{PO}_{3}\right)-\mathrm{OH}$ are commercially available. The deprotection of the Fmoc group was performed with a $20 \%$ piperidine solution in $\mathrm{N}, \mathrm{N}$ dimethylformamide. The deprotection of the $\mathrm{N}^{\alpha}$-function was carried out using a $20 \%$ piperidine solution in DMF, while for the activation of the carboxylic groups, a HBTU/HOBt mixture in a 2 -fold molar excess was used in the presence of a 4-fold excess of DIPEA. On-resin $\mathrm{N}^{\alpha}$-acetylation was achieved using an $\mathrm{Ac}_{2} \mathrm{O} /$ DIPEA mixture in DMF. For the fluorescent analogues, the introduction of the CF probe was carried out on resin and required the preactivation of 5(6)carboxyfluorescein in the presence of HBTU, HOBT, and DIPEA, repeating the acylation step twice. The fluorescent analogues were obtained as a mixture of isomers. At the end of the synthesis, each peptide was cleaved from the resin using a mixture of TFA, TIS, and water in a 95:2.5:2.5 ratio. The filtrates were collected and concentrated under a flow of nitrogen, and the crude peptide was 
precipitated by addition of diethyl ether. The crude peptides were purified by flash chromatography on an Isolera Prime chromatographer (Biotage, Uppsala, Sweden) using a SNAP Cartridge KP-C18HS $12 \mathrm{~g}$ or preparative RP-HPLC on a Phenomenex C18 column $(22.1 \mathrm{~mm} \times 250 \mathrm{~mm}, 10 \mu \mathrm{m}, 300 \AA)$ using an Akta Pure GE Healthcare (Little Chalfont, U.K.) LC system equipped with an ultraviolet detector (flow rate of $15 \mathrm{~mL} / \mathrm{min}$ ) and a binary elution system: $\mathrm{A}, \mathrm{H}_{2} \mathrm{O} ; \mathrm{B}, \mathrm{CH}_{3} \mathrm{CN} / \mathrm{H}_{2} \mathrm{O}[9: 1(\mathrm{v} / \mathrm{v})]$; gradient from $25 \%$ to $55 \% \mathrm{~B}$ in $30 \mathrm{~min}$. The purified fractions were characterized by analytical HPLC-MS on a Phenomenex Kinetex XB-C18 column (4.6 $\mathrm{mm} \times 100 \mathrm{~mm}, 3.5 \mu \mathrm{m}, 100 \AA$ ) with an Agilent Technologies (Santa Clara, CA) 1260 Infinity II HPLC system and a 6130 quadrupole LC/ MS instrument. High-resolution mass spectra were recorded using an ESI-Q-Tof Micro (Waters) spectrometer, in fast injection flow (50\% $\mathrm{ACN} /$ water with $0.1 \%$ formic acid) and positive mode. As indicated in Table 1, all compounds were $>95 \%$ pure, except for three compounds that had purities of $92-93 \%$ and were not used in biological testing.

Peptides were dissolved in DMSO to obtain 1-1.5 mM stock solutions. The exact concentration was obtained by ultraviolet (UV) measurements, exploiting the signal of CF for the labeled peptides and of pTyr, Tyr, and Trp for the unlabeled peptides. To this end, CFlabeled peptides were diluted from the stocks $(1: 100)$ in a buffer $(\mathrm{pH}$ 9 ), and their concentration was calculated from the CF signal at 490 $\mathrm{nm}$ using a molar extinction coefficient of $78000 \mathrm{M}^{-1} \mathrm{~cm}^{-1} .84$ Unlabeled peptides were diluted 1:10 in a $\mathrm{pH} 7.4$ buffer; molar extinction coefficients of Tyr, Phe, and Trp were taken from ref 85, while the molar extinction coefficient of $\mathrm{pY}$ was taken from ref 86 .

Protein Expression and Purification. The human esaHis-tagged PTPN11 (residues 1-528) cDNA was cloned in a pET-26b vector (Novagen). Nucleotide substitutions associated with NS or leukemia were introduced by site-directed mutagenesis (QuikChange sitedirected mutagenesis kit, Stratagene, San Diego, CA). A construct containing the cDNA encoding the isolated PTP domain preceded by the C-SH2 domain (residues 105-528) was generated by PCR amplification of the full-length wild-type cDNA and subcloned into the $\mathrm{pET}-26 \mathrm{~b}$ vector $\left(\mathrm{SHP}_{\Delta 104}\right)$. A similar procedure was followed for the constructs of the $\mathrm{N}-\mathrm{SH} 2$ (residues 2-111), C-SH2 (residues 109-217), and PTP (residues 212-528) domains and of the N-SH2/ $\mathrm{C}$-SH2 tandem (residues 2-217). Primer sequences are available upon request.

Recombinant proteins (wild type, mutants, and isolated domains) were expressed in Escherichia coli (DE3) Rosetta2 competent cells (Novagen), according to the following protocol described in ref 36. Briefly, following induction with isopropyl $\beta$-D-1-thiogalactopyranoside (Roche) $\left(2 \mathrm{~h}\right.$ at $30{ }^{\circ} \mathrm{C}$ or overnight at $\left.18{ }^{\circ} \mathrm{C}\right)$, bacteria were centrifuged at $5000 \mathrm{rpm}$ and $4{ }^{\circ} \mathrm{C}$ for $15 \mathrm{~min}$. Bacterial pellets were resuspended in a lysozyme-containing lysis buffer $[50 \mathrm{mM}$ Tris- $\mathrm{HCl}$ (pH 8.5), $0.5 \mathrm{M} \mathrm{NaCl}, 20 \mathrm{mM}$ imidazole, $1 \mathrm{mM}$ tris(2-carboxyethyl)phosphine (TCEP), $100 \mathrm{mg} / \mathrm{mL}$ lysozyme, and one tablet of complete protease inhibitor cocktail] and sonicated in an ice bath, to avoid the heating of the sample. The lysate was centrifuged at $16000 \mathrm{rpm}$ and $4{ }^{\circ} \mathrm{C}$ for $30 \mathrm{~min}$. The supernatant was collected, and the protein of interest was purified by affinity chromatography on a Ni-NTA column (Qiagen, Hilden, Germany), using a buffer consisting of $50 \mathrm{mM}$ Tris- $\mathrm{HCl}, 0.5 \mathrm{M} \mathrm{NaCl}$, and $1 \mathrm{mM}$ TCEP containing $20 \mathrm{mM}$ imidazole for equilibration, 25 and $100 \mathrm{mM}$ imidazole for washing, and $250 \mathrm{mM}$ imidazole for elution. To remove imidazole, the samples were then dialyzed in a $20 \mathrm{mM}$ Tris- $\mathrm{HCl}$ (pH 8.5) buffer containing $1 \mathrm{mM}$ TCEP, $1 \mathrm{mM}$ EDTA, and $50 \mathrm{mM} \mathrm{NaCl}$ (or $150 \mathrm{mM} \mathrm{NaCl}$ if no further purification steps followed). Fulllength proteins and the $\mathrm{SHP}_{\Delta 104}$ construct were then further purified by sequential chromatography, using an Äkta FPLC system (Äkta Purifier 900, Amersham Pharmacia Biotech, Little Chalfont, U.K.). The samples were first eluted within an anion exchange Hi-Trap QP 1 $\mathrm{mL}$ column (GE Helathcare, Pittsburgh, PA); the elution was carried out using $20 \mathrm{mM}$ Tris- $\mathrm{HCl}(\mathrm{pH} 8.5$ ) in a $\mathrm{NaCl}$ gradient from 50 to $500 \mathrm{mM}$. The most concentrated fractions were then eluted in a gel filtration Superose column using $20 \mathrm{mM}$ Tris- $\mathrm{HCl}$ buffer containing $150 \mathrm{mM} \mathrm{NaCl}$ as the mobile phase. Sample purity was checked by sodium dodecyl sulfate-polyacrylamide gel electrophoresis with Coomassie Blue staining and was always $>90 \%$. Proteins were quantitated by both the Bradford assay and the UV absorbance of aromatic residues, calculating extinction coefficients according to Pace. ${ }^{85}$ In general, the two methods were in agreement, but the values derived from UV absorbance were more precise and are reported in the figures and tables. The protein samples were used immediately after purification or stored at $-20{ }^{\circ} \mathrm{C}$ and used within one week. In this case, after the samples had been thawed, $2.5 \mathrm{mM}$ TCEP was added, the samples were centrifuged at $13000 \mathrm{rpm}$ for $20 \mathrm{~min}$, and the new concentration was re-evaluated. In the few cases in which the residual apparent absorbance due to light scattering was present in the UV spectra, it was subtracted according to Castanho. ${ }^{87}$

Phosphatase Activity Assays. Catalytic activity was evaluated in vitro using $20 \mathrm{pmol}$ of purified recombinant proteins in $200 \mu \mathrm{L}$ of reaction buffer supplemented with $20 \mathrm{mM} p$-nitrophenyl phosphate (Sigma) as the substrate, either basally or following stimulation with the protein tyrosine phosphatase non-receptor-type substrate 1 (PTPNS1) bisphosphotyrosyl-containing motif (BTAM peptide) (GGGGDIT-pY-ADLNLPKGKKPAPQAAEPNNHTE-pY-ASIQTS) (Primm, Milan, Italy), as previously described. ${ }^{22}$ Proteins were incubated for $15 \mathrm{~min}\left(\mathrm{SHP}_{\Delta 104}\right)$ or $30 \mathrm{~min}(\mathrm{SHP} 2)$ at $30{ }^{\circ} \mathrm{C}$. Phosphate release was assessed by measuring the absorbance at 405 $\mathrm{nm}$. Three replicates were performed for each measurement.

The ability of SHP2 to dephosphorylate the phosphopeptides was evaluated through a malachite green phosphatase assay (PTP assay kit 1, Millipore). The BTAM peptide and the following monophosphorylated peptides derived from known SHP2 substrates were used for comparison: DKQVE-pY-LDLDL $\left(\mathrm{GAB}_{\mathrm{Y} 657}\right)$, EEENI-pYSVPHD (p190A/RhoGAP ${ }_{\text {Y1105 }}$ ), and VDADE-pY-LIP $\overline{Q Q}$ $\left(E_{\text {GFR }}{ }_{1016}\right)$ (Primm). SHP2 ${ }_{\Delta 104}(2.4 \mathrm{pmol})$ was incubated with each phosphopeptide at $100 \mu \mathrm{M}$ (total volume of $25 \mu \mathrm{L}$ ) for different times. The reaction was stopped by adding $100 \mu \mathrm{L}$ of a malachite green solution. After $15 \mathrm{~min}$, the absorbance was read at $655 \mathrm{~nm}$, using a microplate reader, and compared with a phosphate standard curve to determine the release of phosphate. Data obtained in the linear region of the curve were normalized to the reaction time ( 1 min). Each experiment was performed in duplicate.

Fluorescence Anisotropy Binding Assay. Anisotropy measurements were carried out using a Horiba Fluoromax 4 spectrofluorimeter. For the binding assays, the requested peptide amount (1 or $0.1 \mathrm{nM})$ was diluted in a buffer $(10 \mathrm{mM}$ HEPES, $150 \mathrm{mM} \mathrm{NaCl}, 1$ mM EDTA, and $1 \mathrm{mM}$ TCEP, fluorescence buffer henceforth) and its anisotropy signal was recorded. The peptide was then titrated with increasing protein amounts, until the anisotropy signal reached a plateau at its maximum value, or up to a protein concentration at which protein aggregation and consequent light scattering affected the anisotropy values (usually $>1 \mu \mathrm{M}$ ). The measurements of CF-labeled peptides were carried out using an excitation wavelength of $470 \mathrm{~nm}$ and collecting the anisotropy values at an emission wavelength of 520 $\mathrm{nm}$. A $495 \mathrm{~nm}$ emission filter was used. For the Cy3-labeled peptides, excitation and emission wavelengths of 520 and $560 \mathrm{~nm}$ were used. The lowest peptide concentration needed to have a sufficient fluorescent signal $(0.1 \mathrm{nM})$ was used in the binding experiments. Higher concentrations ( 1 or $10 \mathrm{nM}$ ) were used for peptides with lower affinities and, therefore, higher $K_{\mathrm{d}}$ values. Between two and six replicates were performed (the specific numbers are indicated in the figures and in the table reporting the binding experiments).

The displacement assays were carried out with the same experimental settings. In this case, the labeled peptide-protein complex was titrated with increasing amounts of the unlabeled peptide, following the decrease in anisotropy. Measurements were carried out at the same CF-peptide concentration used for the corresponding binding experiments. With regard to the protein concentration, a compromise between two requirements is needed. ${ }^{88}$ On one hand, it is desirable to have a significant fraction of the CFpeptide bound to the protein, to maximize the dynamic range in the anisotropy signal, which decreases during the displacement experiment. On the other hand, the protein concentration should be comparable to or lower than the dissociation constant of the 
unlabeled peptide $\left(K_{\mathrm{d}}^{\mathrm{u}}\right)$, to allow a quantitative and reliable determination of its binding affinity. Because several unlabeled peptides had a higher affinity than their fluorescent counterparts, in the displacement assays we used a protein concentration $[\mathrm{P}]_{\mathrm{T}}$ that approximated $K_{\mathrm{d}}$ or in some cases even approximated $K_{\mathrm{d}} / 2$ (where $K_{\mathrm{d}}$ is the dissociation constant for the labeled peptide). Between three and five replicates were performed (the specific numbers are indicated in the figures reporting the binding experiments). The equations used for data fitting are described in the Supporting Information.

SH2 Domain Microarray. The microarray experiment was conducted by the Protein Array and Analysis Core at The University of Texas M. D. Anderson Cancer Center (Houston, TX), as previously described. ${ }^{89}$ Briefly, a library of $\mathrm{SH} 2$ domains ${ }^{90}$ was expressed as a GST fusion in E. coli and purified on glutathionesepharose beads. The domains were spotted onto nitrocellulosecoated glass slides (Oncyte Avid slides, Grace Bio-Laboratories) using a pin arrayer. Each domain was spotted in duplicate. After incubation with a Cy3-P9W5 solution $(0.5,5.0$, or $50 \mathrm{nM})$, fluorescence signals were detected using a GeneTACTM LSIV scanner (Genomic Solutions).

In Silico Studies. System Preparation. The initial structure of the N-SH2 complexed with phosphopeptide P8 (Table 2) was obtained by amino acid substitutions (and deletions) in the crystallographic structure of the protein complexed with the GAB1 peptide (sequence of GDKQVE-pY-LDLDLD) (PDB entry 4QSY). The obtained complex was then used as the starting structure for subsequent amino acid substitutions in the bound peptide.

System Equilibration. MD simulations were performed using the GROMACS 2018.2 simulation package ${ }^{91}$ and a variant of AMBER99SB force field with parameters for phosphorylated residues. ${ }^{92}$ Water molecules were described by the TIP3P model. All of the simulated systems were inserted into a pre-equilibrated triclinic periodic box $(15 \mathrm{~nm} \times 7 \mathrm{~nm} \times 7 \mathrm{~nm})$, containing $\sim 24000$ water molecules and counterions to neutralize the total charge of the system. They were relaxed first by doing a minimization with 5000 steepest descent cycles, by keeping protein positions fixed and allowing water and ions to adjust freely, followed by a heating protocol in which the temperature was progressively increased from 100 to $300 \mathrm{~K}$. The system was then equilibrated for $100 \mathrm{ps}$ in the NVT ensemble at $300 \mathrm{~K}$, using velocity rescaling with a stochastic term (relaxation time of $1 \mathrm{ps})^{93}$ and then for $500 \mathrm{ps}$ at a constant pressure $(1 \mathrm{~atm})$ using the Parrinello-Rhaman barostat (relaxation time of 5 ps). Long-range electrostatic interactions were calculated using the particle mesh Ewald method, and the cutoff distance for the nonbonded interaction was set to $12.0 \AA$. The LINCS constraint to all of the hydrogen atoms and a $2 \mathrm{fs}$ time step were used.

Preparation of the Initial Configurations for Umbrella Sampling. For each system, a set of initial configurations was prepared by performing a center-of-mass (COM) pulling simulation. The distance between the peptide and $\mathrm{N}-\mathrm{SH} 2$ domain $\mathrm{COMs}$ was constrained with a harmonic force $\left(K=1000 \mathrm{~kJ} \mathrm{~mol}^{-1} \mathrm{~nm}^{-2}\right)$. Pulling was performed by gradually increasing the value of the equilibrium distance with a constant rate of $0.0025 \mathrm{~nm} / \mathrm{ps}$. The length of each simulation was $\sim 2.5$ ns. During the whole simulation, a positional restraint $(1000 \mathrm{~kJ}$ $\mathrm{mol}^{-1} \mathrm{~nm}^{-2}$ ) was applied to all heavy atoms in the N-SH2 domain except for atoms in loops around the binding region (residues 30-45, $52-75$, and $80-100)$. For the choice of the optimal unbinding pathway, three different directions were tested, corresponding to (i) the vector from the phosphate to the $\alpha$-carbon in $\mathrm{pY}$, in the equilibrated complex; (ii) the vector defined by the initial positions of the two COMs; and (iii) the vector perpendicular to the surface of the cavity flanked by the EF and BG loops, passing through the N-SH2 domain center of mass. Among the three different pathways, the third direction encountered less steric occlusion by the EF and BG loops and was thus selected for further analyses.

Umbrella Sampling Simulations. A set of starting configurations was extracted from the pull-dynamics trajectory saving the peptideprotein center-of-mass distances every $2 \AA$ in the range from 9 to $\sim 40$ $\AA$, thus affording $\sim 20$ windows along the COM distance. The system in each window was preliminarily equilibrated for $1 \mathrm{~ns}$ with a strong positional restraint $\left(1000 \mathrm{~kJ} \mathrm{~mol}^{-1} \mathrm{~nm}^{-2}\right)$ to all $\alpha$-carbon atoms except for those in loops flanking the binding region (as in the pull simulation), followed by a production run of $150 \mathrm{~ns}$ with the restraints. During this stage, a harmonic potential $\left(K=1000 \mathrm{~kJ} \mathrm{~mol}^{-1}\right.$ $\mathrm{nm}^{-2}$ ) was applied on the distance between the two COMs. Additional sampling windows were added every ångström along the distance between the two COMs up to a distance of $15 \AA$. The resulting asymmetric distribution of sampling windows was used to calculate the PMF on the production run trajectories. The Weighted Histogram Analysis Method (WHAM) was used, with default settings (50 bins and tolerance of $10^{-6} \mathrm{~kJ} \mathrm{~mol}^{-1}$ ), using the gmx wham GROMACS tool. The analysis of the simulation was carried out on the $150 \mathrm{~ns}$ production dynamics, during which configurations were stored every $0.1 \mathrm{~ns}$. The statistical uncertainty of the obtained PMF was estimated by bootstrapping analysis. ${ }^{94}$

Peptide Stability in Serum and in DMEM. The peptides were dissolved in DMSO $(5 \mathrm{mg} / \mathrm{mL})$. In Eppendorf tubes, $1 \mathrm{~mL}$ of HEPES buffer $(25 \mathrm{mM}, \mathrm{pH} 7.6)$ was temperature equilibrated at $37^{\circ} \mathrm{C}$ before the addition of $250 \mu \mathrm{L}$ of human serum and $20 \mu \mathrm{L}$ of a peptide solution; the reaction was followed for $24 \mathrm{~h}$. At fixed intervals, $100 \mu \mathrm{L}$ of the solution was withdrawn and added to $200 \mu \mathrm{L}$ of absolute ethanol. These samples were kept on ice for $15 \mathrm{~min}$ and then centrifuged at $13000 \mathrm{rpm}$ for $5 \mathrm{~min}$; the supernatant solutions were analyzed by HPLC and HPLC-MS with a $20 \%$ to $60 \%$ B gradient in $20 \mathrm{~min}$ to follow the reaction. In parallel, samples containing peptide, buffer, and ethanol only were analyzed. A degradation resistance test was also conducted in DMEM (Dulbecco's modified Eagle's medium). The experimental conditions are similar to those described above; the reaction was followed for $72 \mathrm{~h}$. The enzymatic degradation resistance tests were followed by HPLC using a $5 \%$ to $50 \%$ B gradient over 20 min.

In Vivo Zebrafish Rescue Experiments. One-cell stage zebrafish embryos were injected with a mixture of $120 \mathrm{ng} / \mu \mathrm{L}$ mRNA encoding either GFP-2A-Shp2-D61G or GFP-2A-Shp2-wild-type (as a control), with or without OP, at final concentrations of $0.3,3$, and $5 \mu \mathrm{M}$ (obtained by injecting $\sim 1 \mathrm{~nL}$ of a concentrated solution and assuming a volume of $\sim 500 \mathrm{~nL}$ for the embryo). ${ }^{95}$ Embryos were selected on the basis of proper GFP expression and imaged at $11 \mathrm{hpf}$ in their lateral position using the Leica M165 FC stereomicroscope. Images were analyzed using Image,${ }^{96}$ by measuring the ratio of the major and minor axis from a minimum of 31 embryos (the number of embryos used for each specific experiment is reported in the figure reporting these data). Statistical analysis was performed in GraphPad Prism, using the analysis of variance (ANOVA) complemented by Tukey's honest significant difference test (Tukey's HSD). To measure the survival of injected embryos, a minimum of 48 embryos per group were grown up to 4 days postfertilization and counted on days 1 and 4. Survival curves were plotted using GraphPad Prism, and the differences between samples were determined using the log rank (Mantel-Cox) test. The number of embryos used for each specific experiment is indicated in the figure reporting these data.

\section{ASSOCIATED CONTENT}

\section{(s) Supporting Information}

The Supporting Information is available free of charge at https://pubs.acs.org/doi/10.1021/acs.jmedchem.1c01371.

Methods (with the derivation of the equation used in the analysis of the binding curves), binding selectivity of CFP9W5 for the two SH2 domains of SHP2 (Figure S1), binding of peptide Cy3-P9W5 to the N-SH2 domain (Figure S2), binding of the nondephosphorylatable peptides CF-OP and OP to the N-SH2 domain (Figure S3), resistance of OP and P8W5 to proteolytic degradation in human serum (Figure S4), dephosphorylation of P8W5 and other phosphopeptides by $\mathrm{SHP}_{\triangle 104}$ (Figure S5), association of CF-OP with the PTP domain (Figure S6), representative images of zebrafish embryos $11 \mathrm{hpf}$ (Figure S7), HPLC profile for 
the OP peptide (Figure S8), and literature values of the IRS-1 pY1172/N-SH2 domain dissociation constant (Table S1) (PDF)

Molecular formula strings (CSV)

\section{AUTHOR INFORMATION}

\section{Corresponding Author}

Lorenzo Stella - Department of Chemical Science and Technologies, University of Rome Tor Vergata, Rome 00133, Italy; @orcid.org/0000-0002-5489-7381; Email: stella@ stc.uniroma2.it

\section{Authors}

Sara Bobone - Department of Chemical Science and Technologies, University of Rome Tor Vergata, Rome 00133, Italy; orcid.org/0000-0001-7975-3803

Luca Pannone - Genetics and Rare Diseases Research Division, Ospedale Pediatrico Bambino Gesù, IRCCS, Rome 00146, Italy; Dipartimento di Oncologia e Medicina Molecolare, Istituto Superiore di Sanità, Rome 00161, Italy

Barbara Biondi - Institute of Biomolecular Chemistry, Padova Unit, CNR, Padova 35131, Italy; 이이.org/0000-00032393-7333

Maja Solman - Hubrecht institute-KNAW and University Medical Center Utrecht, Utrecht 3584 CT, The Netherlands Elisabetta Flex - Dipartimento di Oncologia e Medicina Molecolare, Istituto Superiore di Sanità, Rome 00161, Italy

Viviana Claudia Canale - Department of Chemical Science and Technologies, University of Rome Tor Vergata, Rome 00133, Italy; (1) orcid.org/0000-0002-2311-1251

Paolo Calligari - Department of Chemical Science and Technologies, University of Rome Tor Vergata, Rome 00133, Italy

Chiara De Faveri - Department of Chemical Sciences, University of Padova, Padova 35131, Italy

Tommaso Gandini - Department of Chemical Sciences, University of Padova, Padova 35131, Italy

Andrea Quercioli - Department of Chemical Science and Technologies, University of Rome Tor Vergata, Rome 00133, Italy; ○ orcid.org/0000-0002-8200-9986

Giuseppe Torini - Department of Chemical Science and Technologies, University of Rome Tor Vergata, Rome 00133, Italy

Martina Venditti - Genetics and Rare Diseases Research Division, Ospedale Pediatrico Bambino Gesù, IRCCS, Rome 00146, Italy

Antonella Lauri - Genetics and Rare Diseases Research Division, Ospedale Pediatrico Bambino Gesù, IRCCS, Rome 00146, Italy

Giulia Fasano - Genetics and Rare Diseases Research Division, Ospedale Pediatrico Bambino Gesù, IRCCS, Rome 00146, Italy

Jelmer Hoeksma - Hubrecht institute-KNAW and University Medical Center Utrecht, Utrecht 3584 CT, The Netherlands

Valerio Santucci - Department of Chemical Science and Technologies, University of Rome Tor Vergata, Rome 00133, Italy; orcid.org/0000-0003-3650-5628

Giada Cattani - Department of Chemical Science and Technologies, University of Rome Tor Vergata, Rome 00133, Italy

Alessio Bocedi - Department of Chemical Science and Technologies, University of Rome Tor Vergata, Rome 00133, Italy
Giovanna Carpentieri - Genetics and Rare Diseases Research Division, Ospedale Pediatrico Bambino Gesù, IRCCS, Rome 00146, Italy; Dipartimento di Oncologia e Medicina Molecolare, Istituto Superiore di Sanità, Rome 00161, Italy

Valentina Tirelli - Centre of Core Facilities, Istituto Superiore di Sanità, Rome 00161, Italy

Massimo Sanchez - Centre of Core Facilities, Istituto Superiore di Sanità, Rome 00161, Italy

Cristina Peggion - Department of Chemical Sciences, University of Padova, Padova 35131, Italy; 이이.org/ 0000-0001-9716-800X

Fernando Formaggio - Institute of Biomolecular Chemistry, Padova Unit, CNR, Padova 35131, Italy; Department of Chemical Sciences, University of Padova, Padova 35131, Italy

Jeroen den Hertog - Institute of Biomolecular Chemistry, Padova Unit, CNR, Padova 35131, Italy; Institute of Biology Leiden, Leiden University, Leiden 2333 BE, The Netherlands; $\odot$ orcid.org/0000-0002-8642-8088

Simone Martinelli - Dipartimento di Oncologia e Medicina Molecolare, Istituto Superiore di Sanità, Rome 00161, Italy

Gianfranco Bocchinfuso - Department of Chemical Science and Technologies, University of Rome Tor Vergata, Rome 00133, Italy; (1) orcid.org/0000-0002-5556-7691

Marco Tartaglia - Genetics and Rare Diseases Research Division, Ospedale Pediatrico Bambino Gesù, IRCCS, Rome 00146, Italy

Complete contact information is available at:

https://pubs.acs.org/10.1021/acs.jmedchem.1c01371

\section{Author Contributions}

S.M., G.B., and M.T. contributed equally to this work.

Notes

The authors declare the following competing financial interest(s): L.S., B.B., G.B., S.M., and M.T. are the inventors of a patent application, filed by the University of Rome Tor Vergata and the Ospedale Pediatrico Bambino Gesù, regarding the molecules described in this article.

\section{ACKNOWLEDGMENTS}

The authors gratefully acknowledge the Protein Array and Analysis Core at The University of Texas M. D. Anderson Cancer Center for performing the $\mathrm{SH} 2$ array experiments. This work was supported by the AIRC Foundation for Cancer Research in Italy (Grants IG19171 and IG24940 to L.S. and IG21614 to M.T.), the Italian Ministry of Education, University and Research (MIUR, Grant PRIN 20157WW5EH_007 to L.S.), Regione Lazio (Grant A03752020-36719 to L.S. and M.T.), the Italian Ministry of Health (Ricerca Corrente 2019 and 2020 to M.T.), the European Program on Rare Diseases (NSEuroNet, to M.T. and J.d.H.), the Partnership for Advanced Computing in Europe (PRACE, Grants 2019204928 and 2017174118 to G.B.), which awarded computational resources at CINECA (Italy) and CINECA (Grant HP10BL5G4C to G.B.). L.P. is a recipient of an AIRC research fellowship. S.B., P.C., G.B., and L.S. dedicate this article to Prof. Antonio Palleschi, on the occasion of his retirement.

\section{ABBREVIATIONS USED}

ALL, acute lymphoblastic leukemia; AMoL, acute monocytic leukemia; CagA, cytotoxicity-associated immunodominant 
antigen; CF, carboxyfluorescein; Cy3, cyanine 3 carboxylic acid; $\mathrm{F}_{2} \mathrm{Pmp}$, phosphonodifluoromethyl phenylalanine; ST, glutathione S-transferase; hpf, hours post fertilization; JMML, juvenile myelomonocytic leukemia; NS, Noonan syndrome; NSML, Noonan syndrome with multiple lentigines; PDB, Protein Data Bank; PPI, protein-protein interaction; PTK, protein tyrosine kinase; PTP, protein tyrosine phosphatase; pY, phosphotyrosine; RTK, receptor tyrosine kinase; SH2, Src homology 2; SHP2, SH2 domain-containing phosphatase 2; shRNA, short hairpin ribonucleic acid.

\section{REFERENCES}

(1) Tajan, M.; de Rocca Serra, A.; Valet, P.; Edouard, T.; Yart, A. SHP2 sails from physiology to pathology. Eur. J. Med. Genet. 2015, 58, $509-525$.

(2) Saxton, T. M.; Henkemeyer, M.; Gasca, S.; Shen, R.; Rossi, D. J.; Shalaby, F.; Feng, G. S.; Pawson, T. Abnormal mesoderm patterning in mouse embryos mutant for the SH2 tyrosine phosphatase Shp-2. EMBO J. 1997, 16, 2352-2364.

(3) Tartaglia, M.; Niemeyer, C. M.; Fragale, A.; Song, X.; Buechner, J.; Jung, A.; Hählen, K.; Hasle, H.; Licht, J. D.; Gelb, B. D. Somatic mutations in PTPN11 in juvenile myelomonocytic leukemia, myelodysplastic syndromes and acute myeloid leukemia. Nat. Genet. 2003, 34, 148-150.

(4) Tartaglia, M.; Martinelli, S.; Cazzaniga, G.; Cordeddu, V.; Iavarone, I.; Spinelli, M.; Palmi, C.; Carta, C.; Pession, A.; Aricò, M.; Masera, G.; Basso, G.; Sorcini, M.; Gelb, B.; Biondi, A. Genetic evidence for lineage-related and differentiation stage-related contribution of somatic PTPN11 mutations to leukemogenesis in childhood acute leukemia. Blood 2004, 104, 307-313.

(5) Chen, Y. N.; LaMarche, M. J.; Chan, H. M.; Fekkes, P.; GarciaFortanet, J.; Acker, M. G.; Antonakos, B.; Chen, C. H.; Chen, Z.; Cooke, V. G.; Dobson, J. R.; Deng, Z.; Fei, F.; Firestone, B.; Fodor, M.; Fridrich, C.; Gao, H.; Grunenfelder, D.; Hao, H. X.; Jacob, J.; Ho, S.; Hsiao, K.; Kang, Z. B.; Karki, R.; Kato, M.; Larrow, J.; La Bonte, L. R.; Lenoir, F.; Liu, G.; Liu, S.; Majumdar, D.; Meyer, M. J.; Palermo, M.; Perez, L.; Pu, M.; Price, E.; Quinn, C.; Shakya, S.; Shultz, M. D.; Slisz, J.; Venkatesan, K.; Wang, P.; Warmuth, M.; Williams, S.; Yang, G.; Yuan, J.; Zhang, J. H.; Zhu, P.; Ramsey, T.; Keen, N. J.; Sellers, W. R.; Stams, T.; Fortin, P. D. Allosteric inhibition of SHP2 phosphatase inhibits cancers driven by receptor tyrosine kinases. Nature 2016, 535, $148-152$.

(6) Prahallad, A.; Heynen, G. J.; Germano, G.; Willems, S. M.; Evers, B.; Vecchione, L.; Gambino, V.; Lieftink, C.; Beijersbergen, R. L.; Di Nicolantonio, F.; Bardelli, A.; Bernards, R. PTPN11 is a central node in intrinsic and acquired resistance to targeted cancer drugs. Cell Rep. 2015, 12, 1978-1985.

(7) Okazaki, T.; Chikuma, S.; Iwai, Y.; Fagarasan, S.; Honjo, T. A rheostat for immune responses: the unique properties of $\mathrm{PD}-1$ and their advantages for clinical application. Nat. Immunol. 2013, 14, $1212-1218$.

(8) Marasco, M.; Berteotti, A.; Weyershaeuser, J.; Thorausch, N.; Sikorska, J.; Krausze, J.; Brandt, H. J.; Kirkpatrick, J.; Rios, P.; Schamel, W. W.; Köhn, M.; Carlomagno, T. Molecular mechanism of SHP2 activation by PD-1 stimulation. Sci. Adv. 2020, 6, No. eaay4458.

(9) Higashi, H.; Tsutsumi, R.; Muto, S.; Sugiyama, T.; Azuma, T.; Asaka, M.; Hatakeyama, M. SHP-2 tyrosine phosphatase as an intracellular target of Helicobacter pylori CagA protein. Science 2002, 295, 683-686.

(10) Hayashi, T.; Senda, M.; Suzuki, N.; Nishikawa, H.; Ben, C.; Tang, C.; Nagase, L.; Inoue, K.; Senda, T.; Hatakeyama, M. Differential mechanisms for SHP2 binding and activation are exploited by geographically distinct Helicobacter pylori CagA oncoproteins. Cell Rep. 2017, 20, 2876-2890.

(11) Tartaglia, M.; Mehler, E. L.; Goldberg, R.; Zampino, G.; Brunner, H. G.; Kremer, H.; van der Burgt, I.; Crosby, A. H.; Ion, A.; Jeffery, S.; Kalidas, K.; Patton, M. A.; Kucherlapati, R. S.; Gelb, B. D.
Mutations in PTPN11, encoding the protein tyrosine phosphatase SHP-2, cause Noonan syndrome. Nat. Genet. 2001, 29, 465-468.

(12) Roberts, A. E.; Allanson, J. E.; Tartaglia, M.; Gelb, B. D. Noonan syndrome. Lancet 2013, 381, 333-342.

(13) Digilio, M. C.; Conti, E.; Sarkozy, A.; Mingarelli, R.; Dottorini, T.; Marino, B.; Pizzuti, A.; Dallapiccola, B. Grouping of multiplelentigines/LEOPARD and Noonan syndromes on the PTPN11 gene. Am. J. Hum. Genet. 2002, 71, 389-394.

(14) Legius, E.; Schrander-Stumpel, C.; Schollen, E.; PullesHeintzberger, C.; Gewillig, M.; Fryns, J. P. PTPN11 mutations in LEOPARD syndrome. J. Med. Genet. 2002, 39, 571-574.

(15) Tartaglia, M.; Gelb, B. D. Disorders of dysregulated signal traffic through the RAS-MAPK pathway: phenotypic spectrum and molecular mechanisms. Ann. N. Y. Acad. Sci. 2010, 1214, 99-121.

(16) Hof, P.; Pluskey, S.; Dhe-Paganon, S.; Eck, M. J.; Shoelson, S. E. Crystal structure of the tyrosine phosphatase SHP-2. Cell 1998, 92, 441-450.

(17) Liu, B. A.; Jablonowski, K.; Raina, M.; Arcé, M.; Pawson, T.; Nash, P. D. The human and mouse complement of $\mathrm{SH} 2$ domain proteins-establishing the boundaries of phosphotyrosine signaling. Mol. Cell 2006, 22, 851-868.

(18) Anselmi, M.; Calligari, P.; Hub, J. S.; Tartaglia, M.; Bocchinfuso, G.; Stella, L. Structural determinants of phosphopeptide binding to the N-terminal Src homology 2 domain of the SHP2 phosphatase. J. Chem. Inf. Model. 2020, 60, 3157-3171.

(19) Keilhack, H.; David, F. S.; McGregor, M.; Cantley, L. C.; Neel, B. G. Diverse biochemical properties of Shp 2 mutants. Implications for disease phenotypes. J. Biol. Chem. 2005, 280, 30984-30993.

(20) Tartaglia, M.; Martinelli, S.; Stella, L.; Bocchinfuso, G.; Flex, E.; Cordeddu, V.; Zampino, G.; van der Burgt, I.; Palleschi, A.; Petrucci, T. C.; Sorcini, M.; Schoch, C.; Foa, R.; Emanuel, P. D.; Gelb, B. D. Diversity and functional consequences of germline and somatic PTPN11 mutations in human disease. Am. J. Hum. Genet. 2006, 78, 279-290.

(21) Bocchinfuso, G.; Stella, L.; Martinelli, S.; Flex, E.; Carta, C.; Pantaleoni, F.; Pispisa, B.; Venanzi, M.; Tartaglia, M.; Palleschi, A. Structural and functional effects of disease-causing amino acid substitutions affecting residues Ala72 and Glu76 of the protein tyrosine phosphatase SHP-2. Proteins: Struct., Funct., Genet. 2007, 66, 963-974.

(22) Martinelli, S.; Torreri, P.; Tinti, M.; Stella, L.; Bocchinfuso, G.; Flex, E.; Grottesi, A.; Ceccarini, M.; Palleschi, A.; Cesareni, G.; Castagnoli, L.; Petrucci, T. C.; Gelb, B. D.; Tartaglia, M. Diverse driving forces underlie the invariant occurrence of the T42A, E139D, I282V and T468M SHP2 amino acid substitutions causing Noonan and LEOPARD syndromes. Hum. Mol. Genet. 2008, 17, 2018-2029.

(23) LaRochelle, J. R.; Fodor, M.; Vemulapalli, V.; Mohseni, M.; Wang, P.; Stams, T.; LaMarche, M. J.; Chopra, R.; Acker, M. G.; Blacklow, S. C. Structural reorganization of SHP2 by oncogenic mutations and implications for oncoprotein resistance to allosteric inhibition. Nat. Commun. 2018, 9, 4508.

(24) Lee, C. H.; Kominos, D.; Jacques, S.; Margolis, B.; Schlessinger, J.; Shoelson, S. E.; Kuriyan, J. Crystal structures of peptide complexes of the amino-terminal SH2 domain of the Syp tyrosine phosphatase. Structure 1994, 2, 423-438.

(25) Tang, K.; Jia, Y. N.; Yu, B.; Liu, H. M. Medicinal chemistry strategies for the development of protein tyrosine phosphatase SHP2 inhibitors and PROTACs degraders. Eur. J. Med. Chem. 2020, 204, 112657.

(26) Mullard, A. Phosphatases start shedding their stigma of undruggability. Nat. Rev. Drug Discovery 2018, 17, 847-849.

(27) Yuan, X.; Bu, H.; Zhou, J.; Yang, C. Y.; Zhang, H. Recent advances of SHP2 inhibitors in cancer therapy: Current development and clinical application. J. Med. Chem. 2020, 63, 11368-11396.

(28) Mostinski, Y.; Heynen, G. J.; López-Alberca, M. P.; Paul, J.; Miksche, S.; Radetzki, S.; Schaller, D.; Shanina, E.; Seyffarth, C.; Kolomeets, Y.; Ziebart, N.; de Schryver, J.; Oestreich, S.; Neuenschwander, M.; Roske, Y.; Heinemann, U.; Rademacher, C.; Volkamer, A.; von Kries, J. P.; Birchmeier, W.; Nazaré, M. From 
pyrazolones to azaindoles: evolution of active-site SHP2 inhibitors based on scaffold hopping and bioisosteric replacement. J. Med. Chem. 2020, 63, 14780-14804.

(29) Tsutsumi, R.; Ran, H.; Neel, B. G. Off-target inhibition by active site-targeting SHP 2 inhibitors. FEBS Open Bio 2018, 8, 14051411.

(30) Garcia Fortanet, J.; Chen, C. H.-T.; Chen, Y.-N. P.; Chen, Z.; Deng, Z.; Firestone, B.; Fekkes, P.; Fodor, M.; Fortin, P. D.; Fridrich, C.; Grunenfelder, D.; Ho, S.; Kang, Z. B.; Karki, R.; Kato, M.; Keen, N.; LaBonte, L. R.; Larrow, J.; Lenoir, F.; Liu, G.; Liu, S.; Lombardo, F.; Majumdar, D.; Meyer, M. J.; Palermo, M.; Perez, L.; Pu, M.; Ramsey, T.; Sellers, W. R.; Shultz, M. D.; Stams, T.; Towler, C.; Wang, P.; Williams, S. L.; Zhang, J.-H.; LaMarche, M. J. Allosteric inhibition of SHP2: identification of a potent, selective, and orally efficacious phosphatase inhibitor. J. Med. Chem. 2016, 59, 77737782.

(31) Bagdanoff, J. T.; Chen, Z.; Acker, M.; Chen, Y. N.; Chan, H.; Dore, M.; Firestone, B.; Fodor, M.; Fortanet, J.; Hentemann, M.; Kato, M.; Koenig, R.; LaBonte, L. R.; Liu, S.; Mohseni, M.; Ntaganda, R.; Sarver, P.; Smith, T.; Sendzik, M.; Stams, T.; Spence, S.; Towler, C.; Wang, H.; Wang, P.; Williams, S. L.; LaMarche, M. J. Optimization of fused bicyclic allosteric SHP2 inhibitors. J. Med. Chem. 2019, 62, 1781-1792.

(32) Sarver, P.; Acker, M.; Bagdanoff, J. T.; Chen, Z.; Chen, Y. N.; Chan, H.; Firestone, B.; Fodor, M.; Fortanet, J.; Hao, H.; Hentemann, M.; Kato, M.; Koenig, R.; LaBonte, L. R.; Liu, G.; Liu, S.; Liu, C.; McNeill, E.; Mohseni, M.; Sendzik, M.; Stams, T.; Spence, S.; Tamez, V.; Tichkule, R.; Towler, C.; Wang, H.; Wang, P.; Williams, S. L.; Yu, B.; LaMarche, M. J. 6-Amino-3-methylpyrimidinones as potent, selective, and orally efficacious SHP2 inhibitors. J. Med. Chem. 2019, 62, 1793-1802.

(33) LaMarche, M. J.; Acker, M. G.; Argintaru, A.; Bauer, D.; Boisclair, J.; Chan, H.; Chen, C. H.; Chen, Y. N.; Chen, Z.; Deng, Z.; Dore, M.; Dunstan, D.; Fan, J.; Fekkes, P.; Firestone, B.; Fodor, M.; Garcia-Fortanet, J.; Fortin, P. D.; Fridrich, C.; Giraldes, J.; Glick, M.; Grunenfelder, D.; Hao, H. X.; Hentemann, M.; Ho, S.; Jouk, A.; Kang, Z. B.; Karki, R.; Kato, M.; Keen, N.; Koenig, R.; LaBonte, L. R.; Larrow, J.; Liu, G.; Liu, S.; Majumdar, D.; Mathieu, S.; Meyer, M. J.; Mohseni, M.; Ntaganda, R.; Palermo, M.; Perez, L.; Pu, M.; Ramsey, T.; Reilly, J.; Sarver, P.; Sellers, W. R.; Sendzik, M.; Shultz, M. D.; Slisz, J.; Slocum, K.; Smith, T.; Spence, S.; Stams, T.; Straub, C.; Tamez, V., Jr; Toure, B. B.; Towler, C.; Wang, P.; Wang, H.; Williams, S. L.; Yang, F.; Yu, B.; Zhang, J. H.; Zhu, S. Identification of TNO155, an allosteric SHP2 inhibitor for the treatment of cancer. J. Med. Chem. 2020, 63, 13578-13594.

(34) Xie, J.; Si, X.; Gu, S.; Wang, M.; Shen, J.; Li, H.; Shen, J.; Li, D.; Fang, Y.; Liu, C.; Zhu, J. Allosteric inhibitors of SHP2 with therapeutic potential for cancer treatment. J. Med. Chem. 2017, 60, 10205-10219.

(35) Wu, X.; Xu, G.; Li, X.; Xu, W.; Li, Q.; Liu, W.; Kirby, K. A.; Loh, M. L.; Li, J.; Sarafianos, S. G.; Qu, C. K. Small molecule inhibitor that stabilizes the autoinhibited conformation of the oncogenic tyrosine phosphatase SHP2. J. Med. Chem. 2019, 62, 1125-1137.

(36) Martinelli, S.; Nardozza, A. P.; Delle Vigne, S.; Sabetta, G.; Torreri, P.; Bocchinfuso, G.; Flex, E.; Venanzi, S.; Palleschi, A.; Gelb, B. D.; Cesareni, G.; Stella, L.; Castagnoli, L.; Tartaglia, M. Counteracting effects operating on Src homology 2 domaincontaining protein-tyrosine phosphatase 2 (SHP2) function drive selection of the recurrent Y62D and Y63C substitutions in Noonan syndrome. J. Biol. Chem. 2012, 287, 27066-27077.

(37) Martinelli, S.; Pannone, L.; Lissewski, C.; Brinkmann, J.; Flex, E.; Schanze, D.; Calligari, P.; Anselmi, M.; Pantaleoni, F.; Canale, V. C.; Radio, F. C.; Ioannides, A.; Rahner, N.; Schanze, I.; Josifova, D.; Bocchinfuso, G.; Ryten, M.; Stella, L.; Tartaglia, M.; Zenker, M. Pathogenic PTPN11 variants involving the poly-glutamine Gln255Gln256-Gln257 stretch highlight the relevance of helix B in SHP2's functional regulation. Hum. Mutat. 2020, 41, 1171-1182.

(38) Shi, Z. Q.; Lu, W.; Feng, G. S. The Shp-2 tyrosine phosphatase has opposite effects in mediating the activation of extracellular signal- regulated and c-Jun $\mathrm{NH} 2$-terminal mitogen-activated protein kinases. J. Biol. Chem. 1998, 273, 4904-4908.

(39) Sha, F.; Gencer, E. B.; Georgeon, S.; Koide, A.; Yasui, N.; Koide, S.; Hantschel, O. Dissection of the BCR-ABL signaling network using highly specific monobody inhibitors to the SHP2 SH2 domains. Proc. Natl. Acad. Sci. U. S. A. 2013, 110, 14924-14929.

(40) Kertesz, A.; Varadi, G.; Toth, G. K.; Fajka-Boja, R.; Monostori, E.; Sarmay, G. Optimization of the cellular import of functionally active SH2-domain-interacting phosphopeptides. Cell. Mol. Life Sci. 2006, 63, 2682-2693.

(41) Yu, Z. H.; Zhang, R. Y.; Walls, C. D.; Chen, L.; Zhang, S.; Wu, L.; Liu, S.; Zhang, Z. Y. Molecular basis of gain-of-function LEOPARD syndrome-associated SHP2 mutations. Biochemistry 2014, 53, 4136-4151.

(42) Machida, K.; Mayer, B. J. The SH2 domain: versatile signaling module and pharmaceutical target. Biochim. Biophys. Acta. Biochim. Biophys. Acta, Proteins Proteomics 2005, 1747, 1-25.

(43) Cerulli, R. A.; Kritzer, J. A. Phosphotyrosine isosteres: past, present and future. Org. Biomol. Chem. 2020, 18, 583-605.

(44) Kuriyan, J.; Cowburn, D. Modular peptide recognition domains in eukaryotic signaling. Annu. Rev. Biophys. Biomol. Struct. 1997, 26, 259-288.

(45) Wagner, M. J.; Stacey, M. M.; Liu, B. A.; Pawson, T. Molecular mechanisms of SH2-and PTB-domain-containing proteins in receptor tyrosine kinase signaling. Cold Spring Harbor Perspect. Biol. 2013, 5, No. a008987.

(46) Marasco, M.; Carlomagno, T. Specificity and regulation of phosphotyrosine signaling through $\mathrm{SH} 2$ domains. J. Struct. Biol.: $X$ 2020, 4, 100026.

(47) Marasco, M.; Kirkpatrick, J.; Nanna, V.; Sikorska, J.; Carlomagno, T. Phosphotyrosine couples peptide binding and SHP2 activation via a dynamic allosteric network. Comput. Struct. Biotechnol. J. 2021, 19, 2398-2415.

(48) Case, R. D.; Piccione, E.; Wolf, G.; Benett, A. M.; Lechleider, R. J.; Neel, B. G.; Shoelson, S. E. SH-PTP2/Syp SH2 domain binding specificity is defined by direct interactions with platelet-derived growth factor beta-receptor, epidermal growth factor receptor, and insulin receptor substrate-1-derived phosphopeptides. J. Biol. Chem. 1994, 269, 10467-10474.

(49) Sugimoto, S.; Wandless, T. J.; Shoelson, S. E.; Neel, B. G.; Walsh, C. T. Activation of the SH2-containing protein tyrosine phosphatase, SH-PTP2, by phosphotyrosine-containing peptides derived from insulin receptor substrate-1. J. Biol. Chem. 1994, 269, 13614-13622.

(50) Ladbury, J. E.; Lemmon, M. A.; Zhou, M.; Green, J.; Botfield, M. C.; Schlessinger, J. Measurement of the binding of tyrosyl phosphopeptides to SH2 domains: a reappraisal. Proc. Natl. Acad. Sci. U. S. A. 1995, 92, 3199-3203.

(51) Fabrini, R.; De Luca, A.; Stella, L.; Mei, G.; Orioni, B.; Ciccone, S.; Federici, G.; Lo Bello, M.; Ricci, G. Monomer- dimer equilibrium in glutathione transferases: a critical re-examination. Biochemistry 2009, 48, 10473-10482.

(52) Kay, L. E.; Muhandiram, D. R.; Wolf, G.; Shoelson, S. E.; Forman-Kay, J. D. Correlation between binding and dynamics at $\mathrm{SH} 2$ domain interfaces. Nat. Struct. Biol. 1998, 5, 156-163.

(53) Huyer, G.; Li, Z. M.; Adam, M.; Huckle, W. R.; Ramachandran, C. Direct determination of the sequence recognition requirements of the SH2 domains of SH-PTP2. Biochemistry 1995, 34, 1040-1049.

(54) Bonetti, D.; Troilo, F.; Toto, A.; Travaglini-Allocatelli, C.; Brunori, M.; Gianni, S. Mechanism of folding and binding of the Nterminal SH2 domain from SHP2. J. Phys. Chem. B 2018, 122, 11108-11114.

(55) De Souza, D.; Fabri, L. J.; Nash, A.; Hilton, D. J.; Nicola, N. A.; Baca, M. SH2 domains from suppressor of cytokine signaling-3 and protein tyrosine phosphatase SHP-2 have similar binding specificities. Biochemistry 2002, 41, 9229-9236.

(56) Imhof, D.; Wavreille, A. S.; May, A.; Zacharias, M.; Tridandapani, S.; Pei, D. Sequence specificity of SHP-1 and SHP-2 
Src homology 2 domains. Critical roles of residues beyond the pY+3 position. J. Biol. Chem. 2006, 281, 20271-20282.

(57) Tinti, M.; Kiemer, L.; Costa, S.; Miller, M. L.; Sacco, F.; Olsen, J. V.; Carducci, M.; Paoluzi, S.; Langone, F.; Workman, C. T.; Blom, N.; Machida, K.; Thompson, C. M.; Schutkowski, M.; Brunak, S.; Mann, M.; Mayer, B. J.; Castagnoli, L.; Cesareni, G. The SH2 domain interaction landscape. Cell Rep. 2013, 3, 1293-1305.

(58) Noguchi, T.; Matozaki, T.; Horita, K.; Fujioka, Y.; Kasuga, M. Role of SH-PTP2, a protein-tyrosine phosphatase with Src homology 2 domains, in insulin-stimulated Ras activation. Mol. Cell. Biol. 1994, 14, 6674-6682.

(59) Burke, J. T. Design and synthesis of phosphonodifluoromethyl phenylalanine (F2Pmp): a useful phosphotyrosyl mimetic. Curr. Top. Med. Chem. 2006, 6, 1465-1471.

(60) Stump, D. G.; Lloyd, R. S. Site-directed mutagenesis of the T4 endonuclease $\mathrm{V}$ gene: role of tyrosine-129 and-131 in pyrimidine dimer-specific binding. Biochemistry 1988, 27, 1839-1843.

(61) Xu, D.; Liu, X.; Yu, W. M.; Meyerson, H. J.; Guo, C.; Gerson, S. L.; Qu, C. K. Non-lineage/stage-restricted effects of a gain-of-function mutation in tyrosine phosphatase Ptpn11 (Shp2) on malignant transformation of hematopoietic cells. J. Exp. Med. 2011, 208, 19771988.

(62) Kratz, C. P.; Niemeyer, C. M.; Castleberry, R. P.; Cetin, M.; Bergsträsser, E.; Emanuel, P. D.; Hasle, H.; Kardos, G.; Klein, C.; Kojima, S.; Stary, J.; Trebo, M.; Zecca, M.; Gelb, B. D.; Tartaglia, M.; Loh, M. L. The mutational spectrum of PTPN11 in juvenile myelomonocytic leukemia and Noonan syndrome/myeloproliferative disease. Blood 2005, 106, 2183-2185.

(63) Araki, T.; Mohi, M. G.; Ismat, F. A.; Bronson, R. T.; Williams, I. R.; Kutok, J. L.; Yang, W.; Pao, L. I.; Gilliland, D. G.; Epstein, J. A.; Neel, B. G. Mouse model of Noonan syndrome reveals cell type-and gene dosage-dependent effects of Ptpn11 mutation. Nat. Med. 2004, 10, 849-857.

(64) Jopling, C.; van Geemen, D.; den Hertog, J. Shp2 knockdown and Noonan/LEOPARD mutant Shp2-induced gastrulation defects. PLoS Genet. 2007, 3, No. e225.

(65) Pawson, T. Protein modules and signalling networks. Nature 1995, 373, 573-580.

(66) Kaneko, T.; Huang, H.; Cao, X.; Li, X.; Li, C.; Voss, C.; Sidhu, S. S.; Li, S. S. Superbinder SH2 domains act as antagonists of cell signaling. Sci. Signaling 2012, 5, No. ra68-ra68.

(67) Koncz, G.; Tóth, G. K.; Bökönyi, G.; Kéri, G.; Pecht, I.; Medgyesi, D.; Gergely, J.; Sármay, G. Co-clustering of Fcgamma and $B$ cell receptors induces dephosphorylation of the Grb2-associated binder 1 docking protein. Eur. J. Biochem. 2001, 268, 3898-3906.

(68) Waksman, G.; Kumaran, S.; Lubman, O. SH2 domains: role, structure and implications for molecular medicine. Expert Rev. Mol. Med. 2004, 6, 1-18.

(69) Bradshaw, J. M.; Grucza, R. A.; Ladbury, J. E.; Waksman, G. Probing the "two-pronged plug two-holed socket" model for the mechanism of binding of the Src SH2 domain to phosphotyrosyl peptides: a thermodynamic study. Biochemistry 1998, 37, 9083-9090. (70) Hu, J.; Liu, J.; Ghirlando, R.; Saltiel, A. R.; Hubbard, S. R. Structural basis for recruitment of the adaptor protein APS to the activated insulin receptor. Mol. Cell 2003, 12, 1379-1389.

(71) Cunnick, J. M.; Mei, L.; Doupnik, C. A.; Wu, J. Phosphotyrosines 627 and 659 of Gabl constitute a bisphosphoryl tyrosine-based activation motif (BTAM) conferring binding and activation of SHP2. J. Biol. Chem. 2001, 276, 24380-24387.

(72) Zhang, S. Q.; Tsiaras, W. G.; Araki, T.; Wen, G.; Minichiello, L.; Klein, R.; Neel, B. G. Receptor-specific regulation of phosphatidylinositol $3^{\prime}$-kinase activation by the protein tyrosine phosphatase Shp2. Mol. Cell. Biol. 2002, 22, 4062-4072.

(73) Gu, H.; Griffin, J. D.; Neel, B. G. Characterization of two SHP2 -associated binding proteins and potential substrates in hematopoietic cells. J. Biol. Chem. 1997, 272, 16421-16430.

(74) Rönnstrand, L.; Arvidsson, A. K.; Kallin, A.; Rorsman, C.; Hellman, U.; Engström, U.; Wernstedt, C.; Heldin, C. H. SHP-2 binds to Tyr763 and Tyr1009 in the PDGF $\beta$-receptor and mediates
PDGF-induced activation of the Ras/MAP kinase pathway and chemotaxis. Oncogene 1999, 18, 3696-3702.

(75) Sugimoto, S.; Lechleider, R. J.; Shoelson, S. E.; Neel, B. G.; Walsh, C. T. Expression, purification, and characterization of SH2containing protein tyrosine phosphatase, SH-PTP2. J. Biol. Chem. 1993, 268, 22771-22776.

(76) Fujioka, Y.; Matozaki, T.; Noguchi, T.; Iwamatsu, A.; Yamao, T.; Takahashi, N.; Tsuda, M.; Takada, T.; Kasuga, M. A novel membrane glycoprotein, SHPS-1, that binds the SH2-domaincontaining protein tyrosine phosphatase SHP-2 in response to mitogens and cell adhesion. Mol. Cell. Biol. 1996, 16, 6887-6899.

(77) Takada, T.; Matozaki, T.; Takeda, H.; Fukunaga, K.; Noguchi, T.; Fujioka, Y.; Okazaki, I.; Tsuda, M.; Yamao, T.; Ochi, F.; Kasuga, M. Roles of the complex formation of SHPS-1 with SHP-2 in insulinstimulated mitogen-activated protein kinase activation. J. Biol. Chem. 1998, 273, 9234-9242.

(78) García-Gómez, R.; Bustelo, X. R.; Crespo, P. Protein-protein interactions: Emerging oncotargets in the RAS-ERK pathway. Trends Cancer 2018, 4, 616-633.

(79) Henninot, A.; Collins, J. C.; Nuss, J. M. The current state of peptide drug discovery: back to the future? J. Med. Chem. 2018, 61, $1382-1414$.

(80) Ye, G.; Nam, N. H.; Kumar, A.; Saleh, A.; Shenoy, D. B.; Amiji, M. M.; Lin, X.; Sun, G.; Parang, K. Synthesis and evaluation of tripodal peptide analogues for cellular delivery of phosphopeptides. J. Med. Chem. 2007, 50, 3604-3617.

(81) Choi, W. J.; Kim, S. E.; Stephen, A. G.; Weidlich, I.; Giubellino, A.; Liu, F.; Worthy, K. M.; Bindu, L.; Fivash, M. J.; Nicklaus, M. C.; Bottaro, D. P.; Fisher, R. J.; Burke, T. R., Jr Identification of Shc Src homology 2 domain-binding peptoid- peptide hybrids. J. Med. Chem. 2009, 52, 1612-1618.

(82) Nasrolahi Shirazi, A.; Tiwari, R. K.; Oh, D.; Banerjee, A.; Yadav, A.; Parang, K. Efficient delivery of cell impermeable phosphopeptides by a cyclic peptide amphiphile containing tryptophan and arginine. Mol. Pharmaceutics 2013, 10, 2008-2020.

(83) Cerulli, R. A.; Shehaj, L.; Tosic, I.; Jiang, K.; Wang, J.; Frank, D. A.; Kritzer, J. A. Cytosolic delivery of peptidic STAT3 SH2 domain inhibitors. Bioorg. Med. Chem. 2020, 28, 115542.

(84) Esbjörner, E. K.; Lincoln, P.; Nordén, B. Counterion-mediated membrane penetration: cationic cell-penetrating peptides overcome Born energy barrier by ion-pairing with phospholipids. Biochim. Biophys. Acta, Biomembr. 2007, 1768, 1550-1558.

(85) Pace, C. N.; Vajdos, F.; Fee, L.; Grimsley, G.; Gray, T. How to measure and predict the molar absorption coefficient of a protein. Protein Sci. 1995, 4, 2411-2423.

(86) Bradshaw, J. M.; Mitaxov, V.; Waksman, G. Investigation of phosphotyrosine recognition by the $\mathrm{SH} 2$ domain of the Src kinase. J. Mol. Biol. 1999, 293, 971-985.

(87) Castanho, M. A.; Santos, N. C.; Loura, L. M. Separating the turbidity spectra of vesicles from the absorption spectra of membrane probes and other chromophores. Eur. Biophys. J. 1997, 26, 253-259.

(88) Huang, X. Fluorescence polarization competition assay: the range of resolvable inhibitor potency is limited by the affinity of the fluorescent ligand. J. Biomol. Screening 2003, 8, 34-38.

(89) Roth, L.; Wakim, J.; Wasserman, E.; Shalev, M.; Arman, E.; Stein, M.; Brumfeld, V.; Sagum, C. A.; Bedford, M. T.; Tuckermann, J.; Elson, A. Phosphorylation of the phosphatase PTPROt at Tyr399 is a molecular switch that controls osteoclast activity and bone mass in vivo. Sci. Signaling 2019, 12, No. eaau0240.

(90) Huang, H.; Li, L.; Wu, C.; Schibli, D.; Colwill, K.; Ma, S.; Li, C.; Roy, P.; Ho, K.; Songyang, Z.; Pawson, T.; Gao, Y.; Li, S. S. Defining the specificity space of the human SRC homology 2 domain. Mol. Cell. Proteomics 2008, 7, 768-784.

(91) Abraham, M. J.; Murtola, T.; Schulz, R.; Pall, S.; Smith, J. C.; Hess, B.; Lindahl, E. GROMACS: High performance molecular simulations through multi-level parallelism from laptops to supercomputers. SoftwareX 2015, 1-2, 19-25.

(92) Homeyer, N.; Horn, A. H.; Lanig, H.; Sticht, H. AMBER forcefield parameters for phosphorylated amino acids in different 
protonation states: phosphoserine, phosphothreonine, phosphotyrosine, and phosphohistidine. J. Mol. Model. 2006, 12, 281-289.

(93) Bussi, G.; Donadio, D.; Parrinello, M. Canonical sampling through velocity rescaling. J. Chem. Phys. 2007, 126, 014101.

(94) Hub, J. S.; De Groot, B. L.; Van Der Spoel, D. g_wham - A free weighted histogram analysis implementation including robust error and autocorrelation estimates. J. Chem. Theory Comput. 2010, 6, 3713-3720.

(95) Kimmel, C. B.; Ballard, W. W.; Kimmel, S. R.; Ullmann, B.; Schilling, T. F. Stages of embryonic development of the zebrafish. Dev. Dyn. 1995, 203, 253-310.

(96) Schneider, C. A.; Rasband, W. S.; Eliceiri, K. W. NIH Image to ImageJ: 25 years of image analysis. Nat. Methods 2012, 9, 671-675. 